Florida International University FIU Digital Commons

$1-7-2009$

\title{
Parent Emotional Functioning, Parent Responsiveness, and Child Adjustment
}

Melody Whiddon

Florida International University, mwhid001@fiu.edu

DOI: $10.25148 /$ etd.FI10022560

Follow this and additional works at: https://digitalcommons.fiu.edu/etd

\section{Recommended Citation}

Whiddon, Melody, "Parent Emotional Functioning, Parent Responsiveness, and Child Adjustment" (2009). FIU Electronic Theses and Dissertations. 223.

https://digitalcommons.fiu.edu/etd/223 


\title{
FLORIDA INTERNATIONAL UNIVERSITY
}

Miami, Florida

PARENT EMOTIONAL FUNCTIONING, PARENT RESPONSIVENESS, AND CHILD ADJUSTMENT

\author{
A dissertation submitted in partial fulfillment of the \\ requirements for the degree of \\ DOCTOR OF PHILOSOPHY \\ in \\ PSYCHOLOGY \\ by \\ Melody Whiddon
}

2009 
To: Dean Kenneth Furton

College of Arts and Sciences

This dissertation, written by Melody Whiddon, and entitled Parent Emotional Functioning, Parent Responsiveness, and Child Adjustment, having been approved in respect to style and intellectual content, is referred to you for judgment.

We have read this dissertation and recommend that it be approved.

William Kurtines

$\begin{array}{r}\text { Mary Levitt } \\ \hline \text { Martha Pelaez } \\ \hline \text { Marilyn Montgomery, Major Professor }\end{array}$

Date of Defense: January 7, 2009

The dissertation of Melody Whiddon is approved.

\begin{tabular}{r}
$\begin{array}{r}\text { Dean Kenneth Furton } \\
\text { College of Arts and Sciences }\end{array}$ \\
\hline Dean George Walker \\
University Graduate School
\end{tabular}

Florida International University, 2009 


\section{DEDICATION}

I would like to dedicate this dissertation to the families that participated in the YFDP research so that future children and families could potentially benefit from these

findings and have a better way. It is my hope that my work will help the non-abused, yet emotionally unhappy, children who so desperately long for authentic happiness through attachment security. 


\section{ACKNOWLEDGMENTS}

I would like to take this opportunity to thank the many people that helped me during my doctoral studies. First and foremost, I would like to express my tremendous gratitude to my mentor, Dr. Marilyn Montgomery. I am extremely grateful for the freedom I was given to develop my own beliefs and research interests, all the while receiving her unwavering support, encouragement, and guidance.

I also wish to thank my committee members, Dr. William Kurtines, Dr. Mary Levitt, and Dr. Martha Pelaez for believing in my research. I could not have asked for a more supportive committee. Additionally, I would like to acknowledge the support of Dr. James Jaccard, who, in addition to teaching me everything I know about SEM through the courses he taught, offered additional time and knowledge so that I could complete these analyses.

Additionally, I would like to acknowledge the hard work and dedication of past research assistants at the Youth and Family Development program whose diligent work contributed to this research project. Among many are Laura Oramas \& Sandra Neptune who coded parent-child interaction data for my dissertation, and Carmen Romanach and Anahi Collado who coded my thesis data and have been great friends and encouragers ever since. This work would not have been possible without the team work of the aforementioned and many other YFDP lab members.

I would like to (alphabetically) express my sincere gratitude to the following people whose friendship and support throughout my education enabled me to complete this work: Irina Castellanos, who, in addition to being a wonderful friend and confidante, listened to, and critiqued, my dissertation proposal practice runs so that I was prepared to 
present to my committee; Kyle Eichas, whose encouragement in academic and personal endeavors has been a blessing; Calonie Gray, who has been my friend and go-to person for SEM questions; Rachel Ritchie, who obtained signatures on my D-5 when I encountered a problem while out of town, and moreover, whose unwavering support has helped me countless times.

Finally, I would like to thank my parents, Charles and Lorena Whiddon, whose love and support throughout my life has brought me to the place at which I am, and Navaeh and Hayley Whiddon who magnify for me the importance of this type of work. 


\title{
ABSTRACT OF THE DISSERTATION \\ PARENT EMOTIONAL FUNCTIONING, PARENT RESPONSIVENESS, AND CHILD ADJUSTMENT
}

\author{
by \\ Melody Whiddon \\ Florida International University, 2009 \\ Miami, Florida \\ Professor Marilyn Montgomery, Major Professor
}

Over the past two decades, interest in the psychological development of children has steadily increased (Beg, Casey, \& Saunders, 2007), presumably because statistics describing childhood psychological illness are alarming. Certain parent interaction styles or behaviors are known to influence child adjustment. According to attachment theory, the reason for these findings is that interaction with a caregiver informs an individual's construction of an internal working model (IWM) of the self in relation to others in the environment. The purpose of this study was to gain a greater understanding of the factors contributing to child adjustment by examining the influence of parents' emotional functioning and parent responsiveness to children’s bids for interaction.

This dissertation tested a multivariate model of attachment-related processes and outcomes with an ethnically diverse sample. Results partially supported the model, in that parent emotional intelligence predicted some aspects of child adjustment. Overall, the study adds to knowledge about how parent characteristics influence child adjustment and provides support for conceptualizing emotional intelligence as a concrete and observable manifestation of the nonconscious attachment IWM. 


\section{TABLE OF CONTENTS}

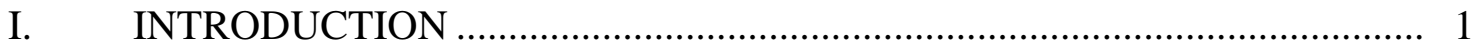

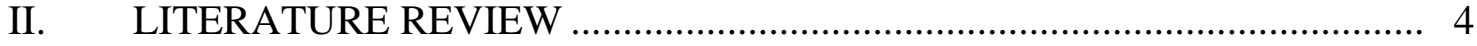

Conceptual Framework: Attachment Theory........................................................ 4

History of Attachment Theory ................................................................. 4

Importance of Attachment Theory ................................................................. 6

Attachment Transmission ........................................................................... 7

Mechanisms of Attachment: Internal Working Models................................. 8

Research on Internal Working Models ......................................................... 11

Parent Emotional Functioning ........................................................................... 13

Parent-Child Interaction ............................................................................... 16

Parent Characteristics and Child Adjustment ................................................. 18

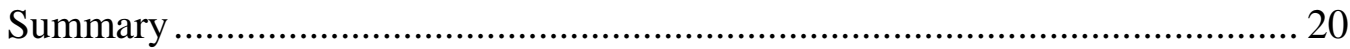

Current Gaps in Literature ............................................................................ 22

Recommendations for Closing the Gaps............................................................ 24

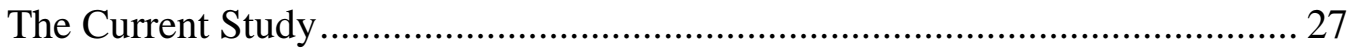

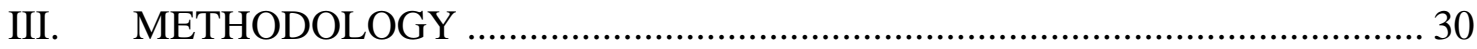

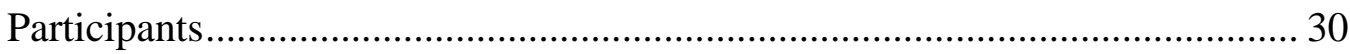

Recruitment Procedures ................................................................................... 30

Assessment Procedures ................................................................................... 31

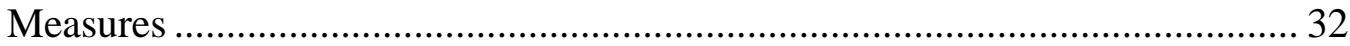

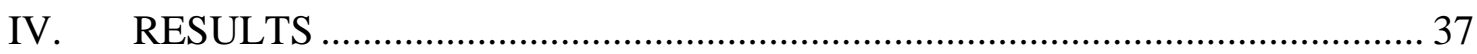

Preliminary Analyses ....................................................................................... 37

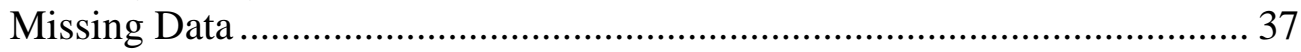

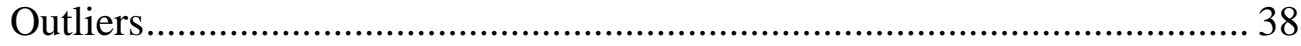

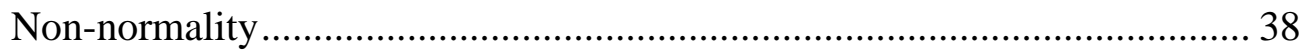

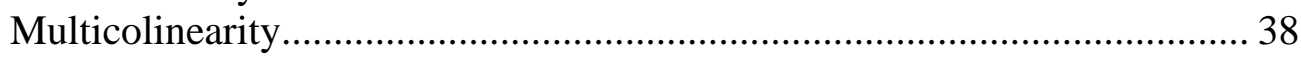

Statistical Power and Sample Size Considerations ...................................... 39

Measurement Error .......................................................................................... 39

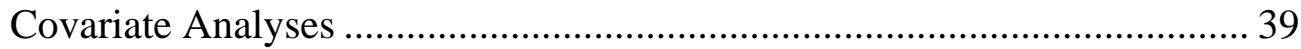

Primary Analyses ........................................................................................ 40

Model Fit Criteria and Evaluation ............................................................ 41

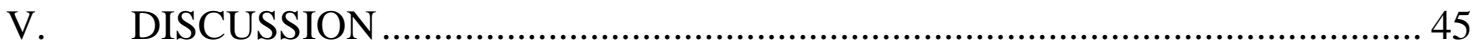

Relationship of Emotional Functioning to Parent Responsiveness .................... 45

Relationship of Parent Responsiveness to Child Psychological Adjustment .... 46

Relationship of Emotional Functioning to Child Psychological Adjustment.... 46

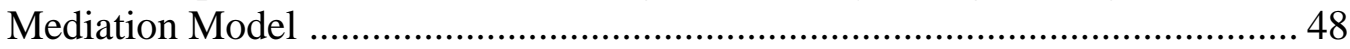

Limitations and Directions for Future Research .................................................. 49 
Conceptual and Clinical Implications .................................................... 50

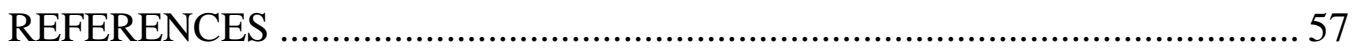

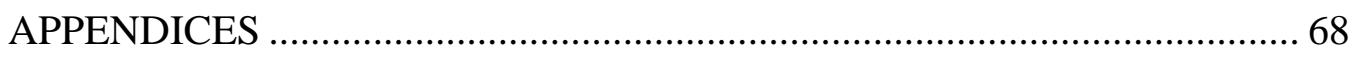

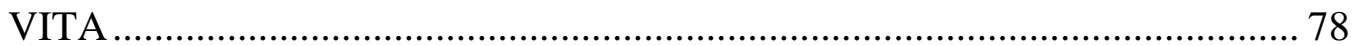




\section{CHAPTER I}

\section{INTRODUCTION}

Beginning at conception, many factors contribute to an individual's adjustment (Propper \& Moore, 2006). Some individuals become secure, happy, competent, and psychologically well-adjusted, but others become withdrawn, anxious, and psychologically disturbed. Although many experiences throughout the lifespan contribute to an individual's adjustment, early experiences have been shown to play a crucial role (Bowlby, 1980). The quality of a child's early interaction with parents has been shown to be one of the most important predictors of later psychological adjustment. The quality of early interactions appears to be particularly related to their social-emotional adjustment (Booth, 2006; Downey \& Coyne, 1990; Skuban, Shaw, \& Nichols, 2006).

Over the past two decades, interest in the psychological development of children has steadily increased (Beg, Casey, \& Saunders, 2007; Cummings \& Davies, 2006), presumably because statistics describing childhood psychological illness are alarming. Twenty percent of children have a diagnosable mental, emotional, or behavioral disorder (NMHA, 2007), half of whom have problems severe enough to significantly interfere with normal functioning and development (Burns, et al., 1995; Shaffer, et al., 1996). Even more shocking, $70 \%$ to $80 \%$ of these children do not receive appropriate mental health services (Burns, et al., 1995; SGRMH, 2000). The World Health Organization speculates that childhood psychiatric disorders will rise by over 50 percent internationally by the year 2020, and become one of the five most widespread causes of morbidity, mortality, and disability among children. 
The causes of childhood psychopathology are difficult to pinpoint because a variety of factors have been shown to have associations with problems that develop from conception onward. While biological, environmental, and experiential factors have all been shown to play a role (Dadds, 1995), the contribution of early experiences to overall psychological adjustment has been theoretically and empirically supported (Bowlby, 1988; see also Bretherton, 1992). Parent factors are often studied when examining childhood psychopathology because of the role parents play in the lives of children with respect to biological, psychological, and contextual influences (Belsky, Lerner, \& Spaniel, 1984). There is a plethora of empirical support for the relationship between parent behavior towards their children and child functioning. Specifically, certain parent interaction styles or behaviors have been associated with child concurrent and future adjustment (Ainsworth et al., 1978; Sanders et al., 1992; Skuban, Shaw, \& Nichol, 2006).

Bowlby, who conceptualized attachment theory, postulated that the reason for these findings is interaction with a caregiver informs an individual's construction of an internal working model (IWM) of the self in relation to others in the environment. This IWM is believed to be a central building block of personality. Moreover, a parent's internal working model leads to the parent's behavior (by guiding the parent's interpretation of and responses to the child's needs) and the quality of the parent-child interaction (synchronous vs. non-synchronous), which is related to the quality of attachment the child has toward the parent (van Ijzendoorn, 1995) which is a reflection of the IWM the child is forming. Thus, typically, there is inter-generational similarity between the IWM of the parent and the IWM formed by the child. 
However, despite empirical support for attachment theory, some gaps in literature still remain. Specifically, the central theoretical hypothesis that parent behavior mediates the relationship between parent IWM and child attachment has yet to receive much empirical support (van Ijzendoorn, 1995), because of difficulties with operationalization and measurement of presumably unconscious processes. In response to calls for research that focus on capturing aspects of parent-child interaction "beyond those encompassed by the traditional notion of sensitivity” (Pederson et al., 1998, p. 931), this study utilizes more concrete, micro-process behaviors as opposed to the non-observable, unconscious process referred to as the IWM, and assesses parent characteristics that should theoretically be related to the IWM. Thus, the current study employs technological advances in behavioral coding techniques to attempt to fill empirical gaps by investigating whether micro-behavioral parent-child interaction, specifically parent response to children's bids for interaction, mediates associations between parent social-emotional functioning (presumed to be an expression of the parent's IWM) and child adjustment (presumed to be evidence of the quality of the child's IWM). 


\section{CHAPTER II}

\section{LITERATURE REVIEW}

The following literature review outlines pertinent theoretical and empirical scholarship that supports the design of the current study. Following the review of the literature is an outline of the shortcomings that plague the field of attachment theory. The chapter concludes with the aims of the present study, which address, in part, several of the shortcomings that exist.

Conceptual Framework: Attachment Theory

History of Attachment Theory. The conception of attachment theory can be traced back to John Bowlby’s early experience with Melanie Klein and psychoanalysis. During his education, his work with maladjusted children, most of whom had negative family environments, alerted him to the vital importance of family experiences in the development of personality and emotional disturbance (Bretherton, 1992). Bowlby acknowledged the idea of instinctual responses, set forth by Freud, that bond infant and mother for the purpose of infant survival. However, Lorenz's (1935) research revealed that the formation of this bond is not necessarily tied to feeding. After much observation and research, Bowlby laid the groundwork for attachment theory, utilizing concepts from ethology, cybernetics, information processing, developmental psychology, and psychoanalysis (Bretherton, 1992).

In 1950, Bowlby hired Mary Ainsworth to analyze his data on hospitalized children who were separated from their parents, based on Ainsworth’s experience observing the relationship of mother-infant pairs in Uganda. Results led to Bowlby's assertion that to grow up mentally healthy, "the infant and young child should experience 
a warm, intimate, and continuous relationship with his mother (or permanent mother substitute) in which both find satisfaction and enjoyment” (Bowlby, 1951, p. 13). Even after the cessation of her work with Bowlby, Mary Ainsworth continued to research attachment and made some major contributions to attachment theory through instrument development and diagnostics. Ainsworth's research on micro-level mother-infant interaction in two studies which became known as the Uganda and Baltimore studies, and infant response to brief separation using a protocol that came to be known as the Strange Situation assessment, revealed 3 distinct attachment categories: Secure, Ambivalent, and Avoidant (Ainsworth, Bell, \& Stayton, 1974). Secure children sought contact with their caregivers upon reunion after the brief separation. When reunited with their caregivers, ambivalent children appeared to desire contact but could not be comforted even when picked up; many further showed their ambivalence by swatting at their caregivers. Avoidant children ignored their returning mothers even though they had searched for her while she was gone (Ainsworth, Bell, \& Stayton, 1974). Further scrutiny revealed that infants who responded to separation with ambivalence or avoidance had a less synchronized relationship with their mothers at home.

Research suggests that differences in the quality of infant-mother interaction are associated with each of the three attachment categories. Ainsworth and others have found associations between the three attachment styles and caregivers' degree of warmth and responsiveness (Ainsworth et al., 1971, 1974, 1978; Blehar, Lieberman, \& Ainsworth, 1977; Maslin \& Bates, 1983; Belsky, Rovine, \& Taylor, 1984; Egeland \& Farber, 1984; Grossmann et al., 1985; Main et al., 1985; Smith \& Pederson, 1988; Crowell \& Feldman, 1988; Pederson et al., 1990; Isabella \& Belsky, 1991; van 
IJzendoorn, 1995). Specifically, maternal sensitivity to child signals and enjoyment of breastfeeding was related to secure attachment, as opposed to mothers who appeared out-of-sync with the needs of their infant (Ainsworth et al., 1971, 1975). Infant behavior varied on the basis of attachment style as well. Infants who were classified as securely attached cried less and were likely to explore their surroundings. These findings suggested the role of the mother as a secure base for exploration of surroundings and a safe haven to which to return (Ainsworth, 1967; Schaffer \& Emerson, 1964). On the other hand, infants classified as insecurely attached did use their mother as a secure base for exploration. Ainsworth concluded that "an infant whose mother's responsiveness helps him to achieve his ends develops confidence in his own ability to control what happens to him” (Bell \& Ainsworth, 1972, p. 1188).

Importance of Attachment Security. A particular attachment style can be extremely relevant to adjustment (Shaver \& Miculincer, 2005). According to attachment theory, secure attachment enables exploration from a secure base. This suggests that children with secure attachment styles will explore their environment more, and thus, become more cognitively competent. Securely attached children should also be more socially competent because of their abilities to explore the social world, since they have learned how to smoothly interact with others and tend to have positive expectations of relationships. There is empirical support to back these theoretical premises. For example, infant attachment security at 15 months of age has been found to be associated with social competency at age three (Waters, Wippman, \& Sroufe, 1979; Clark \& Ladd, 2000; Schneider, Atkinson, \& Tardif, 2001). Attachment security has also been shown to relate to emotional development. Kochanska (2001) assessed children multiple times 
from age 9 to 33 months in situations designed to elicit fear, anger, and joy. Insecurely attached children showed increasingly more negative emotions as they aged, while securely attached children showed decreasing levels of both anger and fear with age.

Additionally, physiology studies have discovered that securely attached infants are better able to cope physiologically with stressful situations (Gunnar, 1998, 2000). The benefits of secure attachment appear to continue as children age. For example, securely attached infants continue to be well-adjusted intellectually, socially, emotionally, and academically during childhood and adolescence (Elicker, Englund, \& Sroufe, 1992; Jacobsen \& Hofmann, 1997; Kerns, Klepac, \& Cole, 1996). An insecure attachment style is related to psychopathology (Egeland \& Carlson, 2004; van IJzendoorn et al., 1999).

Attachment Transmission. From the inception of attachment theory, Bowlby believed that the connection between attachment and psychopathology was anything but simple or linear (Sroufe, Carlson, Levy, \& Egeland, 1999). He specified several propositions about the way early experiences related to attachment and psychopathology. Attachment theory was defined as a pattern of organized behaviors in regards to a relationship, not an inborn trait (Sroufe \& Fleeson, 1986). Furthermore, it was posited that "early experience frames, but also is transformed by, later experience" (Sroufe, Carlson, Levy, \& Egeland, 1999, p. 1; see also Levitt, 2005; Bowlby, 1969). Being on a certain trajectory, or pathway, even early on, does not guarantee a final outcome but rather predisposes one for a set of possibilities, and "cause is probabilistic, not deterministic” (Sroufe, Carlson, Levy, \& Egeland, 1999, p. 3). However, the longer a particular pathway or trajectory is followed, the more improbable is a change in paths. 
While change remains possible, it is more difficult by the time an individual has reached adolescence if he or she has remained on the same path (Bowlby, 1973). The longer a maladaptive trajectory is followed the greater likelihood of psychopathology, with increasing severity. Empirical investigations show support for these premises. Erickson, Egeland, and Sroufe (1985) found that despite histories of anxious attachment, some children showed less severe outcomes because of increased stability of social support for the attachment figure (which presumably led to changes in parent characteristics), thus suggesting that the internal working model can be changed through supportive experiences. In summary, attachment theory does not posit that early experiences cause certain outcomes. Rather, psychopathology, from the attachment perspective, is believed to be a joint product of early attachment (which is influenced by biological and contextual factors) and then subsequent support or challenge (Sroufe, Carlson, Levy, \& Egeland, 1999) and the quality of relationships with important others (St. Clair \& Wigrin, 2004).

Mechanisms of Attachment: Internal Working Models. According to attachment theory, the mechanism by which parent-child interaction leads to psychopathology is through the internal working model (IWM). Bowlby proposed that social interaction with a caregiver leads to the construction of an IWM of the self in relation to the environment; the IWM in turn is thought to be among the central building blocks of personality development (Bowlby, 1973). Attachment scholars argue for the influence of the internal working model (IWM) to attachment and its transmission from parent to child (Ainsworth, Blehar, Waters, \& Wall, 1978; Berlin \& Cassidy, 2000; Bowlby, 1973, 1980, 1982; van Ijzendoorn, 1995) via the "transmission model” (van Ijzendoorn, 1995). 
According to this model, a parent's IWM of attachment plays a key role in driving parenting behaviors during parent-child interaction, which then contribute to the quality of parent-child attachment by guiding the parent's interpretations of and responses to the needs of the child (Berlin, Ziv, Amaya-Jackson, \& Greenberg, 2005; Main, 1990). Through his or her behavioral and emotional reactions, the primary attachment figure (most often, but not always, a mother) non-consciously "trains" the baby in the first year of life to avoid certain behaviors that make him or her uncomfortable. For example, parents can communicate their discomfort or disapproval of their child's behavior by stating it verbally (i.e., “don’t do that”), by displaying it with their facial expression (i.e., a smile or a frown), or by ignoring or dismissing it (i.e., looking away, changing the subject). These parent's responses, which are more or less synchronous with the child's behavior and needs, are thought to form the child's internal working model of attachment (Berlin, Ziv, Amaya-Jackson, \& Greenberg, 2005), which in turn influences the child's experience of self and others.

Optimally, parents' behaviors, driven by their internal working models, are predominantly sensitive and supportive rather than insensitive and unresponsive. A sensitive parent is open and accepting of the full range of child needs and responds contingently, whereas an insensitive parent is thought to distort and/or respond selectively to child bids for feeding, soothing, interaction, and so forth (Ainsworth et al., 1978). Sensitive parenting is thought to lead to the ideal "secure" attachment, characterized by the child's internal working model of the attachment figure as a "secure base from which to explore” (Ainsworth, 1963). 
According to Bowlby (1980), a child's IWM acts as a guide for later interpersonal relationships through an influence on expectations, feelings, and patterns of behavior (Slade \& Aber, 1992; Diamond \& Blatt, 1994). Infants whose needs for both contact and exploration are regularly unmet generally develop an IWM of others as bad (unreliable and uncaring) and the self as bad (unlovable, unworthy, and incompetent), and as adults, disappoint themselves and expect each new person to prove uncaring and unresponsive. On the other hand, children whose needs have consistently been met in a loving and supportive manner construct IWMs that guide them to view others as good (dependable and trustworthy) and themselves as good (loveable, competent, and attractive), and as adults, optimistically engage in relationships and other interests (Bretherton, 1992; Levy \& Blatt, 1999). The development of an internal working model facilitates the child's insight into the attachment figure's motives and hence, the choice of response (Bretherton, 1992). Bowlby posited that sufficient internal working models lead to an accurate perception of the present and expectations of the future, whereas inadequate working models do not and lead to psychopathology. Hence, securely attached children (who have had optimal interactions with their attachment figure) with positive IWMs enjoy better mental health and greater wellbeing, both in childhood and later life.

Bowlby emphasized the role of internal working models in the intergenerational transmission of attachment patterns, as the working model of the attachment figure tends to be congruent with that of the child. Furthermore, unlike the psychoanalytic view of his time which emphasized infantile fantasy, Bowlby postulated that internal working models are "tolerably accurate reflections of the experiences those individuals actually had" (Bowlby, 1973, p. 235). The IWM in general, and related pattern of interpersonal 
responding, is believed to affect a person throughout life. Research has found evidence for the stability of the IWM over time as the view of self and others and interpersonal expectations that were constructed as a child are resistant to change (Levy \& Blatt, 1999). However, similar to attachment style, IWMs are not immutable, and can change with different interpersonal experiences (Levitt, 2005; Levitt, 1991; Levitt, Guacci-Franco, \& Levitt, 1993), but do appear to be influential for most people (Bowlby, 1969; Collins \& Read, 1994). Thus, as notes previously, a particular pathway resulting from early attachment is "probabilistic, not deterministic" (Sroufe et al., 1999, p.3)

In summary, internal working models are thought to be the building blocks of personality development (Bowlby, 1980). Specifically, parents’ IWMs are related to their behaviors during interaction, and facilitate the development of the child's IWM of self and others. These working models are related to certain attachment styles, which are in turn associated with various types of psychological strengths or symptoms (Shaver \& Mikulincer, 2005).

Research on Internal Working Models. Van IJzendoorn conducted a series of meta-analyses on the associations between parents’ internal working models, parent behavior, and parent-child attachment. Results indicated robust associations between parents’ working models and infant attachment category (De Wolff \& Van IJzendoorn, 1997; Van IJzendoorn, 1995), strong associations between parents’ internal working models and sensitive, warm and supportive parent behavior (Van IJzendoorn, 1995), and moderately strong associations between parent sensitive behavior and infant attachment (De Wolff \& Van IJzendoorn, 1997). While there is support for direct links between parents’ internal working models, parent behavior (e.g., sensitivity), and parent-child 
attachment--the specific hypothesis that parent behavior mediates the relationship between parents' internal working models and child attachment security—has not yet received strong empricial support (De Wolff \& Van IJzendoorn, 1997; Van IJzendoorn, 1995; Pederson, Gleason, Moran, \& Bento, 1998). This direct path from parent IWM to child attachment that is not accounted for by parent behavior is known as the “transmission gap” (van IJzendoorn, 1995).

Belsky and others have postulated that it is important to consider the transmission model in context and in conjunction with other factors known to play a role in child development (Belsky, 1999a; Belsky, Rosenberger, \& Crnic, 1995). For example, there is empirical support for associations between family stress, parent mental health, social support, and child or parent health and parents' internal working models, parent behavior, and attachment style (Berlin, Ziv, Amaya-Jackson, \& Greenberg, 2005). These findings suggest that there are indirect effects of other factors on attachment, through internal working models (Belsky, 1999a; Belsky, Rosenberger, \& Crnic, 1995; Berlin \& Cassidy, 1999). However, research findings are still unclear regarding the contributions of these other factors and how they may or may not interact with parents' internal working models and behavior.

Furthermore, it is not the degree of sensitivity that a caregiver is capable of that is telling, but rather the behavior that characterizes the caregiver the majority of the time that is thought to have a lasting impact upon the child (Berlin, Ziv, Amaya-Jackson, \& Greenberg, 2005). For this reason, global sensitivity (i.e., measured by one overall value assigned for degree/intensity of sensitivity) may not be an optimal marker of attachment. Sensitivity, measured as such, may rarely be more than moderately related to empirical 
assessments of attachment security, and hence may not account for the link between maternal IWM and child attachment security (Berlin, Ziv, Amaya-Jackson, \& Greenberg, 2005). Rather, as some have begun to argue, research should focus on capturing aspects of parent-child interaction "beyond those encompassed by the traditional notion of sensitivity” (Pederson et al., 1998, p. 931).

\section{Parent Emotional Functioning}

The construct of emotional competence shares similarities with the internal working model of attachment, as defined within the attachment theory framework. Both constructs deal with interpreting one's own and others' emotions, sometimes referred to as emotional regulation, and using this information to guide behavior (Levy \& Blatt, 1999; Salovery \& Mayer, 1990). Additionally, both are ways to operationalize positive inter- and intra-personal functioning, which is one prerequisite of secure attachment. Thus, it seems plausible to assume that one's emotional competence is related to, and even indicative of, one’s IWM. Accordingly, in this study parents' emotional functioning will be viewed as a indicator of the IWM.

As noted above, a parent's IWM is thought to influence the parent's beliefs about self and other and expectations for relationships, and hence, is influential in their interpersonal and intrapersonal functioning (and associated symptoms). One way that inter- and intra-personal functioning has been examined is by looking at constructs that have been colloquially termed “Emotional Intelligence.” Descriptions of psychopathology (particularly depression) are more widely detailed, researched, and consequently used in psychological studies than are descriptions of optimal inter- and intra-personal functioning (Seligman, Rashid, \& Parks, 2006) However, recently, more 
attention has been given to conceptualizing and operationalizing more broad aspects of positive functioning and there has been a significant rise in prevention efforts.

One stream of research that has attempted to do so, and which is receiving increasing attention, has used the conceptual metaphor of "emotional intelligence” to capture aspects of positive emotional functioning, or lack thereof.

The concept of Emotional Intelligence, or “EI,” has roots that can be traced back to Darwin (1872), who acknowledged the role of emotional expression for survival and adaptation. However, the presently well-known term, "Emotional Intelligence" (EI), was not coined until 1985, by Wayne Payne in his unpublished work. Thus, The first theoretical account of the presently-known term "Emotional Intelligence" is generally attributed to Salovey and Mayer (1990), who defined the construct as "the ability to monitor one's own and others' feelings and emotions, to discriminate among them and to use this information to guide one's thinking and actions” (p. 199). In the 1990's, the release of Daniel Goleman's work on Emotional Intelligence facilitated public interest and research gained momentum, particularly in the arena of work outcomes. One EI researcher, Reuven Bar-On, was the first scientist to use the term "Emotional Quotient” (Bar-On, 2006). Bar-On posits that EI, which develops over time and can be improved through training or therapy, is "an array of noncognitive abilities, competencies, and skills that influence one's ability to succeed in coping with environmental demands and pressures” (Bar-On, 1999, p. 16). More specifically, he denotes the importance of effectively understanding oneself and others. An individual's success in life is determined by a combination of emotional intelligence and other factors (Bar-On, 1999). 
After many years of research, Bar-On (1999) developed the EQ-I scale to measure a number of constructs related to emotional intelligence, to determine an overall estimate of one's emotional and social intelligence and specifically, their intrapersonal and interpersonal functioning, adaptability, stress management, and general mood. The intrapersonal scale is made up of items assessing self regard, emotional self-awareness, assertiveness, independence, and self-actualization. The interpersonal scale includes items assessing empathy, social responsibility, and interpersonal relationships. Measures of reality-testing, flexibility, and problem-solving make up the adaptability scale. The stress management scale includes items assessing stress tolerance, and impulse control. The final subscale, general mood, is made up of items assessing optimism and happiness. Thus, emotional intelligence is one way of measuring positive functioning, and theoretically, should be related to certain features of parent beliefs and behaviors when interacting with their children.

Emotional intelligence is thought to be learned from parents during the childhood years (Mayer \& Salovey, 1997). The development of high EI is dependent on parents' ability, acquired from their past own experiences, to instill in their children an understanding of emotions and an ability to utilize emotion to facilitate thought and problem solving (Roberts, Zeidner, \& Matthews, 2001).The interaction of emotions pertinent to EI begins with the dyadic relationship that develops soon after birth. The nature of the mother-child relationship, which is a guide for later interpersonal relationships, develops as a result of the regular interaction patterns (Tsujino \& Oyama-Higa, 2007). A sensitively responsive mother facilitates the development of a very smooth, synchronous exchange with her child. Subsequently, the infant patterns his 
or her behavior after that of the mother. Children with emotionally healthy, sensitive mothers learn to accurately interpret and deal with their own and others' emotions. Parent-Child Interaction

Parent-child interaction quality is often studied by attachment theorists and practitioners alike because of its crucial influence on a child's adjustment. "Parent-child interaction is increasingly recognized as an important focus of early intervention programs, as research has shown that the interaction between a parent and child is important to optimal child development” (Barnard \& Kelly, 1990, p. 278). It is generally defined as "two or more people engaging in a mutual exchange of thoughts and ideas in which both participants are contributing and responding to each other" (Russo \& Owens, 1982, p.166).

The study of parent-child interaction is important because of the clues it provides about the past and present and its implications about the future. Observing the interaction of parent and child allows the trained eye to infer the attachment style of the child (Ainsworth, 1978), which permits the researcher or clinician to deduce the IWMs of both parent and child. Observing parent-child interaction can also provide clues about concurrent and future adjustment in both members of the dyad. For example, poorly adjusted (e.g., clinically depressed) mothers are known to interact with their children quite differently than well-adjusted mothers (Tarullo, 1994). In a recent study examining parent-child interaction, Tarullo (1994) found that mother and child behavior were both strongly linked to maternal mental status and to child problem behavior. Additionally, she found that young children and preadolescents were less engaged and appeared less comfortable during interaction with affectively ill mothers. Therefore, by considering the 
theoretical ramifications of a particular style of interaction, inferences and predictions can be made about the parent and child's current and future adjustment.

Positive interaction between parent and child is often described by trained observers as a flowing, “coordinated interaction” (Kerns, 1994). Harrist and Waugh (2002) further explain that it is possible for two people who are closely attached, such as parent and child, to show and perceive in each other the following characteristics: shared sustained foci of attention, shared understanding, mutually high positive affect, mutually positive appropriate bids and responses, mutually respectful deference and receptivity, mutually enjoyable interactions, shared relatively moderate intensities of arousal, and high levels of positive, contingent, sensitive responsiveness and attunement. Thus, when optimal parent-child interaction occurs, both partners co-regulate each other and appear to be operating as one dyad rather than two individuals involved in turn-taking or non-contingent behaviors (Fogel, 1993). According to theoretical premises, the degree and quality of the interaction (i.e., parents sensitively responding to children's bids) is a key component in the transmission of the IWM from parent to child.

Parent characteristics, namely sensitive attunement and responsiveness, appear to be a vital component in the development of a synchronous parent-child relationship (Isabella \& Belsky, 1991; Kochanska, 2002; Skuban et al., 2006). As expected, children of synchronous parent-child dyads are more likely to have secure attachments to their parents than are children of dys-synchronous dyads (Isabella et Belsky, \& von Eye, 1989). Moreover, children who display high levels of synchrony is their relationships with their parents have been found to have greater competence and display fewer behavior problems at all developmental periods (Criss et al, 2003; Feldman, Greenbaum, 
\& Yirmiya, 1999; Harrist et al., 1994; Lindsey, Mize, \& Pettit, 1997). Hence, parent-child interaction appears to be a window into the intra- and inter-personal adjustment of both individuals.

Through empirical investigation, several specific parent behaviors or characteristics have been shown to promote secure attachment, and the development of an adequate internal working model in the child. In general, these behaviors are maternal sensitivity, responsiveness, and parent and child mutual enjoyment of engagement (Ainsworth et al., 1978). Parental sensitivity is often described in terms of taking the child's perspective, engaging or following the child's lead nonintrusively, showing positive affect, accurately perceiving and responding to bids and signals from the child, and showing a balance between providing comfort or independence, depending on the need of the child at that time (Ainsworth et al., 1978). Children are wired for interaction and make bids on their parents in efforts to engage them in talk or play. Thus, sensitive parents should be aware of, and engagingly respond to, the bids of their children with contextual appropriateness. Complementarily, certain child behaviors are related to, and can be viewed as markers of, parent behaviors. Specifically, children whose parents perceive and respond to their bids with less accuracy may display more bids during interaction due to increased efforts for an appropriate response.

Parent Characteristics and Child Adjustment

As highlighted in this review, much empirical research is consistent with propositions about the importance of the characteristics of the attachment figure (generally the parent) in the interaction, attachment relationship and subsequent internal working models that shape a person throughout the lifespan. Early on, Bowlby 
emphasized the role of external factors, such as social networks, economic status, and health factors, in the parent's ability to display the behavior necessary for the child's secure attachment (Bretherton, 1992). He argued persuasively that the inheritance of mental health through family experiences is perhaps more important than genetic inheritance (Bowlby, 1973, p. 323). He advocated strongly for society's support of families, as seen in his very powerful statement that "if a community values its children it must cherish their parents” (Bowlby, 1951, p. 84).

A closer look at poorly-adjusted mothers, specifically those suffering from depression, as an example of mothers with one common type of psychopathology, illustrates how parent characteristics and resulting responsiveness (or lack thereof) to a child impact child functioning. It is well-known that children of depressed mothers are at an increased risk for psychopathology (Birmaher et al., 1996; Cicchetti \& Toth, 1995, 1998; Weinfield, Sroufe, Egeland, \& Carlson, 1999). Specifically, these children have been shown to display more negative affect, poorer affect regulation, more behavior and social problems, and poorer cognitive functioning (Carter, Garrity-Rokous, ChazenCohen, Little, \& Briggs-Gowan, 2001; Cicchetti, Rogosch, \& Toth, 1998; DeMulder \& Radke-Yarrow, 1991). Parent behavior during interaction with the child may be a linking mechanism, as depressed mothers have been shown to be less sensitive, proactive, and engaging (Campbell, Cohn, \& Myers, 1995; Carter et al., 2001; DeMulder \& RadkeYarrow, 1991; Godman \& Gotlib, 2002). Additionally, and as would be expected of children with less responsive caregivers, children with depressed mothers have higher rates of insecure attachment (Campbell, Cohn, Myers, Ross, \& Flanagan, 1993). Other studies have documented the relationship between insecure attachment and future 
behavior problems (Easterbrooks, Davidson, \& Chazin, 1993). Thus, integrating findings such as these, it seems plausible that barriers to the development of secure attachment, which are likely in mothers with depressive disorders, may be a key contributor to the emergence of later psychopathology (Cummings \& Cicchetti, 1990). In summary, children of poorly adjusted mothers are at increased risk for future psychopathology, and evidence suggests that early attachment insecurity may play a contributing role (Toth, Rogosch, Manly, \& Cicchetti, 2006).

While parent functioning is known to play a key role in the development of an attachment relationship (and underlying IWM), and subsequent child psychopathology, most research has examined maternal depression as a key construct. One limitation of these narrowly-focused studies is that while "maternal depression" is a single clinical label, a determination of this diagnosis is based on a broad and varied range of maternal symptoms, all of which are related to overall emotional functioning (e.g., physical symptoms - appetite change, weight change, sleep change, psychomotor changes, fatigue and psychological symptoms--depressed mood, feelings of worthlessness/guilt, loss of interest, decreased concentration/memory, suicidal ideation, DSM-IV TR, 2000) and the IWM. Few studies have examined the specific aspects of interpersonal functioning that are impaired in depression—or that are present in emotional competence and wellbeing-- and how they relate to child adjustment.

\section{Summary}

As noted in Chapter One, child psychopathology is a steadily-increasing concern. As noted in this chapter, one body of research that seeks to understand different trajectories involved in social-emotional development by examining parent-child 
interactions is attachment theory (Propper \& Moore, 2006). Specifically, attachment theory suggests the importance of parent characteristics to parent-child interaction and subsequent child adjustment (Bowlby, 1973). The IWM of the parent is hypothesized to be the key factor in whether or not parent behaviors are supportive of secure attachment (e.g., sensitive to, and responsive of, the needs and wants of the child) and furthermore, the qualities of IWM the child develops (Bretherton, 1992). Secure attachment and healthy adjustment require an IWM that includes accurate perceptions about self, other, and the world, meaningful goals, and effective strategies for accomplishing goals (Antonovsky, 1987).

Specifically, attachment literature posits that early interaction with a caregiver is internalized in the form of an IWM, which frames and guides personality development and subsequent future attachments or relations (Bowlby, 1980). The patterns of observable interactive behavior that stem from the internal working model of both parent and child (which tend to be congruent) have been classified and labeled a particular style of attachment (i.e., secure, insecure-anxious, insecure-avoidant, disorganized) on the basis of their appropriateness and synchrony (Ainsworth, 1967; Ainsworth, 1974; Schaffer \& Emerson, 1964). Furthermore, these attachment styles are believed to remain relatively stable throughout development, assuming conditions remain relatively steady (Main, et al., 1985). The exploration and validation of (as well as failure support) these premises have driven much research, as they continue to be of interest to researchers today. 


\section{Current Gaps in Literature}

Despite impressive advances in theory and methods since the inception of attachment theory, significant gaps remain. From its foundation, attachment theory has been investigated through partial tests of the theory which included many methodological limitations (Karen, 1994). Homogeneous samples of middle class white mothers limit claimed universality and generalizability to other social classes or ethnic groups with known differences in parenting practices. Furthermore, many advances that have been utilized in other areas of psychology have been slow to be used in attachment-related research, yet offer promising potential for investigating its premises. New technology permits more precise and systematic computer-based observational measurements of interactive behavior and advances in measurement, including multiple methods techniques and advanced multivariate statistical analysis techniques, which enable the researcher to examine links between constructs in more conceptually sophisticated and analytically sensitive ways (Wilcox, 2002). For example, structural equation modeling allows for the proposal and evaluation of causal models, while taking into account measurement error (Jaccard \& Wan, 1996).

Additionally, theoretically based premises have not been consistently supported. Accordingly, it is still unclear which parent characteristics lead parents to act in sensitive ways, or ways which are conducive to secure attachment. For example, parent sensitive behavior, which is postulated as a major defining characteristic as to whether or not they are "good enough” (Winnicott, 1953) has had weak to moderate associations with theoretically linked variables (Ainsworth, Blehar, Waters, \& Wall, 1978; De Wolff \& van IJzendoorn, 1997). It is plausible that it is not the degree of sensitivity a parent is capable 
of but rather the degree of sensitivity that they exhibit the majority of the time that is telling (Berlin et al., 2005). At this time, research from the attachment perspective should aim to map out the specific processes that are theorized in attachment theory. Specific behavioral, emotional, cognitive, and social traits and behaviors in parents associated with features of interaction with their child should be observed. Such observable, micro-level behaviors that are presumably present during parent-child interaction may prove more fruitful measures of the broad terms such as "parent characteristics" or even "parent internal working model.” In general, current theoretical postulates should be carefully considered and operationalized in a way that permits empirical explorations. While many processes of attachment theory have been theoretically outlined, specific mechanisms that drive and determine such processes have yet to be spelled out. Questions still remain regarding the specific mechanisms that cause and/or account for the various associations that have been empirically denoted (Cummings, Davies, \& Campbell, 2000). From the beginning, attachment researchers have attempted to account for processes through a diverse variety of theoretical and methodological operationalizations (e.g., Biringen’s Emotional Availability Scales which attempted to bridge several closely-related theories), and have made key contributions. Yet, fitting all the pieces together in the most meaningful way has proven challenging. Research using more precise operationalizations of terms and processes may prove to be more fruitful.

A synthesis of all presently-known attachment-related literature suggests that gaps exist regarding parent characteristics that facilitate secure attachment-related behavior, as well as the processes that account for the parent behaviors and the child's development and maintenance of an attachment style and subsequent psychological adjustment. 
While, theoretically, the IWM is presumed to be the mechanism linking an individual's attachment style and their social and emotional functioning, the IWM has proven difficult, if not impossible, to assess. The IWM is often construed as a nonconscious aspect of individual personality, which leads to a conundrum as to how a nonconscious entity can be measured through self-report, which tends to represent conscious processes. Most research on the IWM has utilized self-report measures on how one functions in relationships (e.g., the Adult Attachment Inventory, Main \& Goldwyn, 1994) which may not be reaching the nonconscious level, but rather a gauging conscious phenomenon. However, it seems plausible to assume that this nonconscious phenomenon is manifested concretely, at least to some degree, in a cognitive and emotional self-regulatory system. The interplay of cognitions and emotions that result from an internal self-regulatory system are more concrete manifestations of attachment and subsequent adaptive or pathological adjustment and are manifested in more observable behaviors. Recommendations for Closing the Gaps

Taking into account the plethora of empirical support for child attachment, the following "all-encompassing" conceptual model seems to be a viable presentation of the “transmission hypotheses” (See Figure 1). Parents’ IWMs are believed to affect their beliefs, expectations, and behaviors, which can be referred to as their worldview. The worldview is manifested more concretely in parent emotional functioning, which is known to play a huge role in parent-child interaction style, or more specifically, emotional synchrony during interaction. This interaction plays a crucial role in the development of the child's IWM and attachment category. The child's IWM impacts his or her beliefs, expectations, and behaviors. Ultimately, this worldview leads to the 
child's adjustment (on a continuum from adaptive to pathological). However, this conceptual model is not fully testable due to the inclusion of several non-observable, inferred latent theoretical constructs. To progress, future research should encompass all testable constructs of the aforementioned model.

Figure 1: Non-testable Conceptual Model

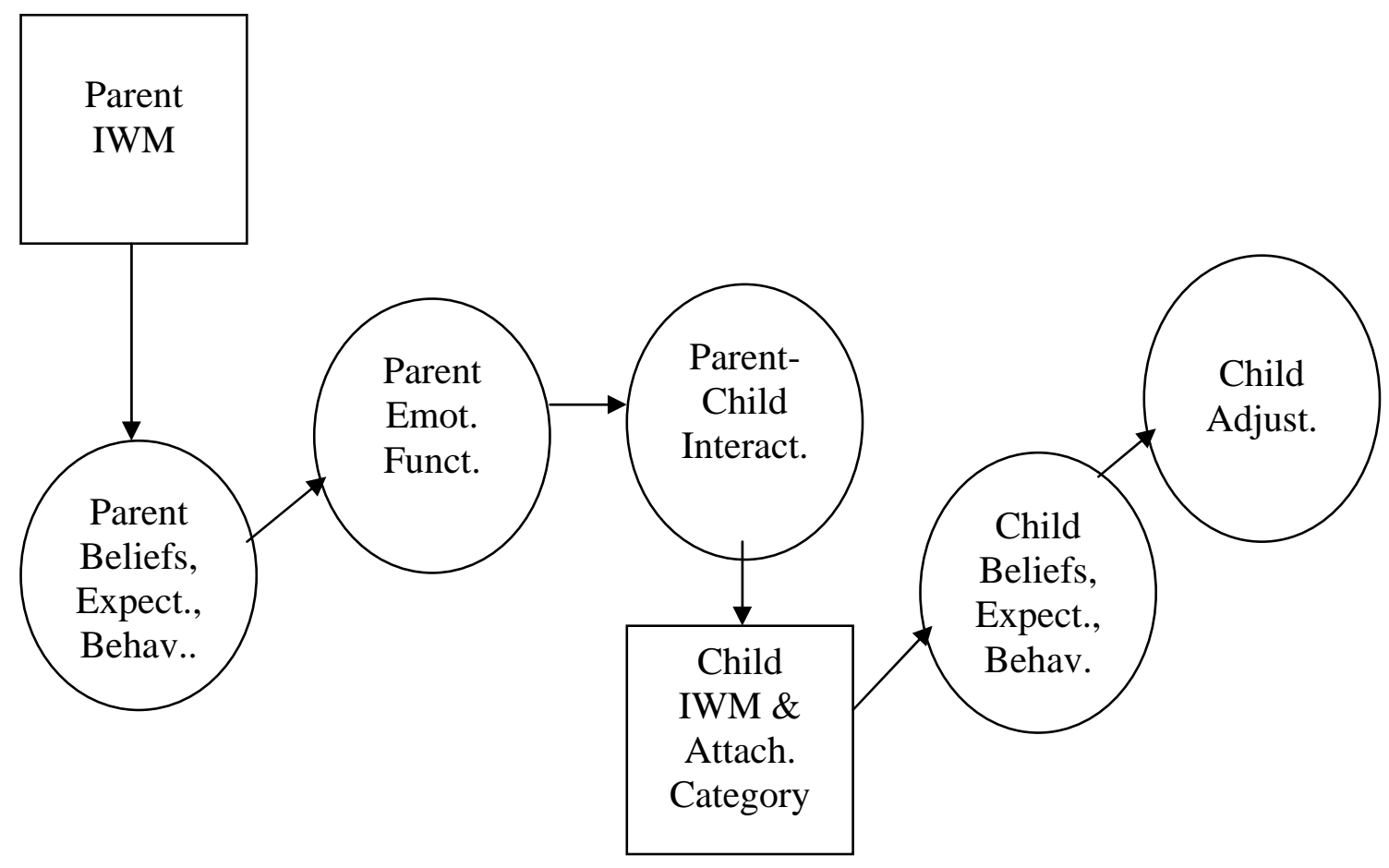

Given the fact that in previous research, parenting behaviors during interaction with their child (i.e., responsiveness accounted for a relatively small proportion of the association between parent's IWM and child adjustment (known as the "transmission gap,” future investigations should include ways to investigate more micro-level associations between more concrete parent factors, observable features during parentchild interaction, and child adjustment in more normative contexts. The development of 
an explanatory model of these relationships is essential if appropriate interventions are to be designed.

Specifically, research might examine the role of parent emotional functioning and associated/inferred internal working model in parent-child interaction, a marker of attachment quality, and furthermore, associations with child psychopathology. Emotional competence and IWM are two distinct constructs with some overlap (see Figure 2). Specifically, it seems viable to postulate that parent emotional competence is linked to, but not entirely accounted for by parent IWM. In this case, close examination of the micro-level parent-child interactive behaviors may provide vital information, as it may suggest details about the phenomenological experience of the child that are influencing their own IWM symptoms/behavior/psychological health or pathology (which would, theoretically, be linked to their own IWM).

Figure 2: Conceptual Causal Model for Child Adjustment

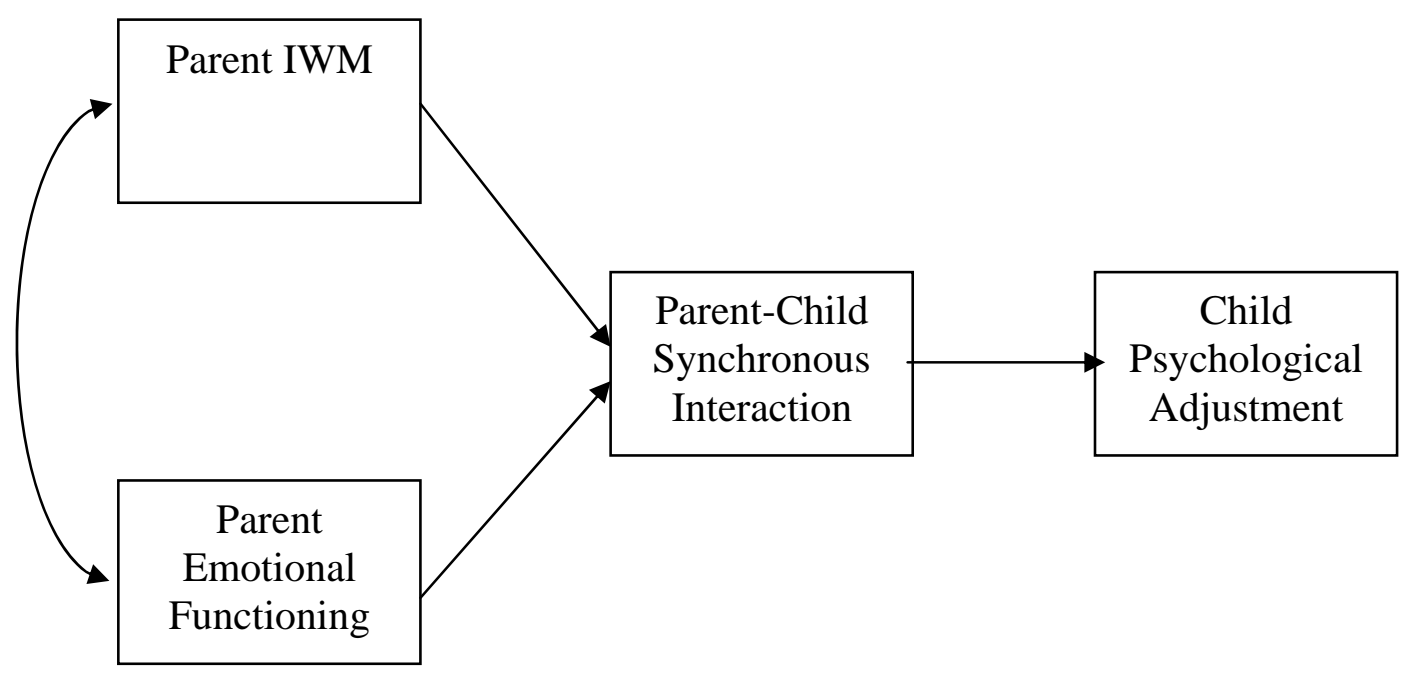

Finally, based on a synthesis of current literature, it seems viable to hypothesize that parent emotional functioning and child psychological functioning are causally 
related, mediated by specific parent-child interactive behaviors, such as emotional synchrony (see Figure 3). Parent's emotional competence may be presumed to be influenced by the parent's IWM, but may be more a plausible and efficient target of measurement and treatment compared to the broad and intrinsically unobservable construct of IWM. Specific aspects of parent-child interaction are known to relate to child psychological functioning, but questions still remain concerning the specific mechanisms that permit parents to interact optimally with a child; parent emotional functioning may be the mechanism whereby parent capacities are brought into the parent-child relationship.

Figure 3: The Proposed Model

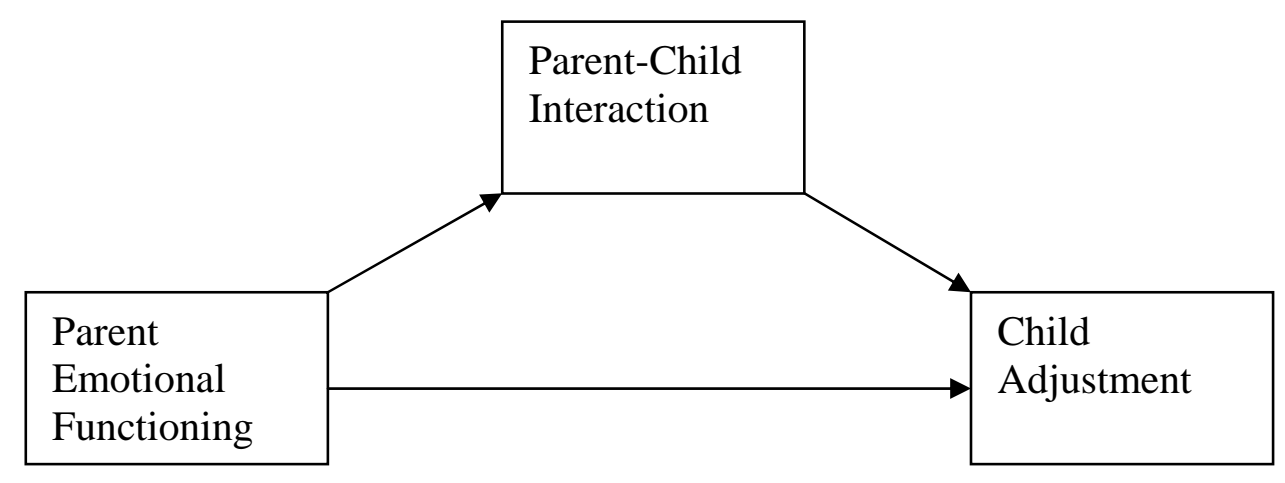

\section{The Current Study}

To synthesize, despite the growth of theory and knowledge about parent-child interaction that can be traced back from Freud's early psychoanalytic theory, many theoretical notions have still not been well-tested. Suggestions for rectifying these gaps in both literature and theory have been suggested above. There is much promise for the future of attachment-related research if researchers take advantage of methodological 
advances in both the study (and subsequent refined operationalizations) of attachment processes and also in analytical strategies and techniques.

To conclude, the current study seeks to take a step towards addressing the empirical and theoretical gaps outlined in this paper in order to facilitate more efficacious prevention and intervention efforts, specifically those geared toward reducing the instances of poor child adjustment and the related increase in rates of child psychopathology (Beg, Casey, \& Saunders, 2007; NMHA, 2007; Shaffer, et al., 1996; SGRMH, 2000; Burns, et al., 1995). Thus, the overarching purpose of this study was to contribute knowledge that can be used to reduce of the number of children who grow up to be withdrawn, anxious, disturbed adults, and increase the number of children who become secure, happy, and competent. Broad questions guiding this study (and a related program of future work) are as follows:

1. Is there a relationship between parent emotional functioning and specific aspects of parent-child interaction? Can parent emotional functioning be used as an observable proxy for the nonconscious, unobservable IWM, which is known to relate to parent-child interaction?

2. Is there a relationship between specific aspects of parent-child interaction and child psychological adjustment? Do specific qualities of interaction predict certain child psychological behaviors?

3. Is there a relationship between parent emotional functioning and child psychological adjustment? Moreover, is this relationship mediated by specific aspects of parent-child interaction? 
Based on these broad research questions, the research aim and hypotheses for this study are as follows:

Research Aim. Develop and empirically test a multivariate model of parent emotional functioning and child psychological adjustment, mediated by parent-child interaction in an ethnically-diverse sample. The literature discussed above summarizes research on links between the key variables in the model. Overall, it was expected that the data would fit the pathway model depicted in Figure 3.

Hypothesis 1. It was hypothesized that parent emotional functioning would predict parent responsiveness to child bids for interaction. Specifically, parents who report greater emotional functioning as measured by the EQ-I were expected to show more observed responsiveness towards their child's bids for interaction.

Hypothesis 2. It was hypothesized that observed parent responsiveness to child bids for interaction would predict child adjustment. Specifically, greater parental responsiveness to child bids for interaction were expected to be associated with more positive child adjustment (i.e., fewer internalizing and externalizing behavior problems).

Hypothesis 3. It was hypothesized that parent emotional functioning would predict child psychological adjustment. Specifically, higher scores on emotional intelligence were expected to be associated with more positive child adjustment (i.e., internalizing and externalizing behavior problems). Additionally, this association was expected to be mediated by parent responsiveness to child bids for interaction. 


\section{CHAPTER III}

\section{METHODOLOGY}

Archival and currently collected data from families seeking developmental assessment at the Youth and Family Development Program (YFDP) at Florida International University were used to investigate the aims of this study. Data were collected under the IRB-approved protocol \#040703-00, “The Child Development and Family Enrichment Project.”

\section{Participants}

A total of 97 parent/child dyads that completed the focal assessments were included in the analyses (Table 1). Children's age ranged from 4 to 12 years with a mean age of 7.60. Sixty-two (63.9\%) of the children were male and thirty-five (36.1\%) were female. Mothers’ age ranged from 21 to 52 with a mean age of 36.71. Seventy-two (74.2\%) of the mothers were married, eleven (11.3\%) were divorced, three (3.1\%) were separated, ten (10.3\%) were single, and one (1\%) did not report her marital status (Table 1). Two (5\%) of the mothers had completed some high school, five (12.5\%) had completed high school, thirteen (32.5\%) had completed some college, sixteen (40\%) had attained bachelor degrees, two (5\%) had attained advanced degrees, and two (5\%) did not report their education levels.

\section{Recruitment Procedures}

As noted above, the data for the current study were obtained as part of an observational study, “The Child Development and Family Enrichment Project,” which was conducted in the YFDP laboratory in the Department of Psychology at Florida 
International University. Parents contacted the YFDP with concerns they had about their child's development or behavior.

Parents who called were given a description of the YFDP services, including the Developmental Assessment, a service routinely offered by YFDP by Counseling Psychology practicum/internship students. Parents were then screened for eligibility to participate in the YFDP laboratory programs, (i.e., the target child must be between 4 and 12 years of age and must not meet diagnostic criteria for certain disorders which were beyond the scope of the YFDP). Families excluded from participation were referred for psychological services at other university-based psychology clinics nearby. Parents were given the opportunity to obtain their Developmental Assessment at a reduced rate in exchange for their participation in the research.

\section{Assessment Procedures}

Regardless of the service desired, all parents and children received a Developmental Assessment, which included a routine assessment battery, during their first two visits. During the first visit, parents gave informed consent for the research study, which included consent for videotaping. Next, the parent-child dyad was administered the Play Tasks Assessment, an observational assessment that was video-recorded through a one-way mirror (see Play Task description in Methods section). After the Play Task Assessment, the child remained in the room for the remainder of the session with one of the therapists while the parent proceeded to another room with another therapist. The child completed age-appropriate assessments that were part of the YFDP routine battery and appropriate to the particular developmental concerns. The parent completed a series of self-report questionnaires included in the YFDP battery. 
Among these assessments were the Child Behavior Checklist (Achenbach \& Edelbrock, 1987) and the Emotional Quotient Inventory-short (Bar-On, 1990), which were used in this study.

Measures

Assessments used in this study focused on four domains: (1) demographic variables, (2) child adjustment (3) parent adjustment, and (4) parent behavior towards the child. Specific instruments and coding manuals used for this study are in the Appendix, and are discussed below.

Background Questionnaire. Participants were asked to report demographics such as age, gender, education, family income, and ethnicity. Parents also provided pertinent information about the target child, including previous psychological diagnoses.

The Child Behavior Checklist. The Child Behavior Checklist (CBCL, Achenbach, 1991; Achenbach \& Edelbrock, 1987) was utilized to measure parents’ perception of child problems such as attention problems, anxiety, and internalizing and externalizing behaviors. See Table 4 for means and standard deviations of all variables. Parents responded to 113 item descriptors, such as “unhappy, sad, or depressed,” and were asked to rate on a $0-2$ scale $(0=$ not true, $1=$ somewhat or sometimes true, and $2=$ very or often true) how well each item characterized their child presently or in the past 6 months. The CBCL has been reported by Achenbach \& Edelbrock (1983) to have an alpha coefficient of .77. A computer scoring program furnished by the Achenbach System of Empirically Based Assessments (ASEBA) calculated internalizing, externalizing, and total problems scales, and the following subscales: Anxious/Depressed, Somatic Complaints, Social Problems, Thought Problems, Attention Problems, Rule-Breaking Behavior, Aggressive 
Behavior, Affective Problems, Anxiety Problems, Somatic Problems, Attention Deficit/Hyperactivity Problems, Oppositional Defiant Problems, and Conduct Problems. The CBCL, which has been widely used in children ages 4 to 16 years old, has a strong empirical base, has been found to have adequate internal reliability with subscale reliability ranging from .78 to .97 , and construct validity for measurement of child problem behaviors and competencies among children ages $1 \frac{1 / 2}{2}$ to 18 years of age (Achenbach. \& Rescorla, 2000, Achenbach \& Edelbrock, 1987; Biederman, Monuteaux, Greene, Braaten, \& Doyle, \& Faraone, 2001; Sheeber \& Johnson, 1994). For the purposes of this study, the internalizing scale, comprised of the anxious/depressed, withdrawn/depressed, and the somatic subscales, and the externalizing scale, comprised of the social problems, thought problems, and attention problems subscales, were used.

Emotion Quotient Inventory-Short (EQ) The EQ-i:S consists of 51 short-sentence items with a 5-point Likert-type response scale ranging from "very seldom or not true of me" (1) to "very often true of me or true of me" (5). The individual's responses provide a total EQ score as well as scores 5 composite subscales: Intrapersonal, Interpersonal, Stress management, Adaptability, and General Mood (Bar-On, 2003).

For the purposes of this study, the EQ total scale, which is a composite of all items, was used to measure parent's overall emotional functioning. Average to above average scores on the $E Q$ suggest that the respondent is effectual in emotional and social functioning, and higher scores indicate more positive predictions for effective functioning in meeting demands and pressures of one's environment. On the other hand, low scores indicate the potential for serious difficulties in coping with normal life demands and stressors on a daily basis. 
The EQ has been shown to have satisfactory reliability across a variety of normative groups, despite the small number of items in each subscale. Internal consistency coefficients ranged from .76 to .93 (Bar-On, 2002). Construct validity estimates between the EQ-i:S used in this study and the 133-item EQ range from .75 to .97 (Bar-On, 2002). In this study, Cronbach's alpha reliability coefficients for the intrapersonal, interpersonal, stress management, adaptability, mood, and total EQ scales were $.75, .76, .87, .86, .87$, and .93 , respectively.

Parent Responsiveness to Child Bids. To test the aims of this study, observational ratings of parent-child interaction were used in addition to self-report and parent-report measures. Observational ratings of parent-child interaction were coded using a computer software package (The Noldus Observer XT 7.0) by viewing samples of parent-child interaction that were video-taped through a one-way mirror.

Because parent sensitivity and responsiveness to their child is a central tenet of attachment theory (Ainsworth, 1963), efforts to include a micro-behavioral, dyadic level variable in the YFDP ongoing research led to the development of a set of variables representing parental responsiveness to child bids for interaction (see Coding Manual, Appendix B). Verbal and nonverbal children's bids were seen, including direct or indirect requests, join/intervene into parents’ activity, or intentional touch or gesture. Parent's responses to these bids were evaluated for contextual appropriateness and rated as accept-engage, accept-acknowledge, ignore, or reject. Parent's response, verbal or nonverbal, of accepting and engaging were assigned a value of 3. Parent's response of accepting minimally simply by acknowledging were assigned a value of 2. Parents who responded to their child's bid by ignoring were assigned a value of 1 and parents 
rejecting responses were assigned a value of 0 . Mean parent responsiveness to child bids was calculated by averaging parents’ response to all bids and used for analyses.

Two extensively-trained undergraduate raters coded the videos together with a detailed coding manual to reference, and discussed ratings to consensus. Any disagreement was discussed to consensus with an arbitrator. Additionally, $20 \%$ of the tapes rated each week were randomly chosen to be independently rated by the investigator, in order to ascertain integrity of the coding scheme as applied by the raters and prevent rater drift. Percent agreement between the coding team and the investigator was required to remain above $80 \%$. All coding met this criterion with a percent agreement ranging from 81.4 to $100 \%$.

Play Task Assessment Description. The Play Task Assessment uses a combination of cooperative problem solving tasks and unstructured free time to capture semi-naturalistic dyadic interaction. This assessment method was chosen in order to facilitate the expression of parent behaviors that most closely represent those evident outside of the laboratory, thereby increasing external validity. Pilot testing of the experimental procedure was conducted to ensure that the sessions were engaging and appropriate to children's cognitive and functional level.

During each observation session the family members were asked to participate in four 5-minute tasks. For the purposes of this study, only the first five minutes of the puppet task was used because this task provided the most opportunity for bid and response interaction between parent and child. A trained experimenter introduced the sessions and tasks. The observation room was equipped with two chairs, a large table, and open spaces for the family members to play. For the first 5 minute task, which was 
used in this study, the participants were given puppets to play with and were left alone to interact. 


\section{CHAPTER IV}

\section{RESULTS}

\section{Preliminary Analyses}

The following section describes the steps that were taken to explore the data prior to conducting SEM analyses. Preliminary analyses included the calculation of descriptive statistic, including means, standard deviations, and skewness and kurtosis levels, and intercorrelations (Table $3 \&$ 4) for all study variables (Table 5). To prepare the data for analyses, the amount and type of missing data was investigated and data were screened for outliers. The normality of the data was assessed and multicolinearity was explored. A power analysis was conducted to estimate the ability of the proposed statistical tests to detect an effect, given an effect exists, and will be described below. Age of parent, age of child, gender of child, ethnicity, and socio-economic status were assessed for appropriateness of inclusion as covariates.

Missing Data. Missing data were minimal for most variables, however, it should be noted that the Emotional Quotient Inventory (EQ) was added to the assessment battery mid-study, after approximately half of the data had been collected. As a result, for the EQ measure, $48 \%$ of the data are missing. These data are "missing by design,” so parameter estimates and model tests were pursued in the context of Full Information Maximum Likelihood (FIML) methods as implemented in AMOS 16. For the infrequent instances of data missing from the other measures, missing data bias was assessed by computing a dummy variable reflecting the presence or absence of missing data for each variable in the model and then correlating this dummy variable with all other variables in the model 
as well as all demographic variables. None of the correlations were statistically significant, which suggests that these data were missing at random.

Outliers. Outlier analyses were undertaken prior to all major analyses, using both non-model based and model based procedures. For non-model based analyses, the presence of multivariate outliers was investigated by examining leverage indices for each individual and defining an outlier as a leverage score four times greater than the mean leverage. The mean leverage score was .35; thus, based on this criterion, no outliers were evident. An additional set of outlier analyses was pursued using model-based outlier analysis. Standardized $d f$-betas were examined for each individual and each predictor as well as the intercept and were found to range from -.42 to .60. An outlier was defined as anyone with an absolute standardized $d f$-beta larger than 1.0 (Wilcox, 1997, 1999, 2003). Based on these criteria, two individuals deemed outliers were omitted from analyses.

Non-normality. Data normality was evaluated using Mardia's test for multivariate normality. In addition, univariate indices of skewness and kurtosis were examined to determine if the absolute value of any of these indices was greater than 2.0. Based on these criteria, most data were deemed normal.

Multicolinearity. Some participants $(n=12)$ were siblings of other participants in this study. To assess for the effect of multicolinearity in the data because of duplicate parent representations for the siblings, siblings were removed from the data and analyses were run. No significant difference in any variable mean or in any association between variables was found so the decision was made to include the sibling participants in the final analyses. 
Statistical Power and Sample Size Considerations. To determine the appropriate sample size needed for structural equation modeling analyses, a limited information approach was used to obtain a rough approximation of statistical power. This technique uses traditional power analysis software to gain a sense of sample size demands (Jaccard \& Wan, 1996). A power analysis was conducted to estimate power for a predictor that accounts for at least $5 \%$ unique variance in the outcome. As shown in the model description in Chapter 2, the maximum number of predictors for a multiple regression analysis was two. A squared multiple correlation of 0.80 was used as a basis for this power analysis, since this was near the lowest squared correlation observed in the modeling. Also, a 0.05 alpha level and a two-tailed test were assumed. A sample size of 77 yielded a power coefficient greater than .80 . The final model included two predictors. This procedure was repeated and it was found that the sample size of 97 yielded a power coefficient of .92 for linear models having two predictors. Therefore, the sample size of 97 used in this study yielded satisfactory power for the analyses conducted.

Measurement Error. Because only single-indicator variables were used, we adopted the strategy suggested by Joreskog and Sorbom (1996) to account for measurement error. This involved constraining the error/unique variances for each measure to values corresponding to a priori determined levels of reliability.

Covariate Analyses. Child gender differences between males and females on all key variables were explored with analyses of variance (ANOVA). Results showed that males and females did not differ significantly on any variable. Analyses were also conducted to determine whether differences between racial ethnic groups were present. 
Results indicated that Hispanics and non-Hispanic Whites did not differ significantly on any variable included in this study.

Correlations were explored between both children's and mother's age and all study variables. Results suggest that the older children were, the more likely their mothers were to perceive them to suffer with anxious/depressed symptoms and to present somatic complaints and conduct problems. In contrast, mothers with older children were less apt to report aggressive tendencies. Thus, considering these findings and the fact that it makes theoretical sense that child age predicts the type of behavior problems they exhibit and their psychological functioning in general, child age was used as a covariate so that its effects were held constant in the context of the tested model.

Primary Analyses

Structural Equation Modeling (SEM) was pursued with AMOS 16.0 because it is an analytic technique that allows for the investigation of direct and indirect relationships between one or more independent variables and one or more dependent variables. The SEM methodology is designed to accommodate models that include latent variables, reciprocal causation, measurement error, interdependence and simultaneity. It is useful for examining multidimensional relationships and is the only analysis that provides complete and concurrent tests of all the relationships. Overall, SEM is a more powerful statistical technique than multiple regression or path analysis, with more flexible assumptions. Unlike more traditional statistical approaches, SEM also considers measurement error (Hoyle \& Panter, 1995; Kline, 1998).

Using structural equation modeling (SEM) for these reasons and because of its ability to separate common and unique components of variance, which minimizes the 
effects of any unreliability due to measurement error, this study tested the mediating model between parent emotional functioning, parent-child interaction, and child psychological functioning depicted in Figure 4.

Model Fit Criteria and Evaluation. Based on the recommendations of Bollen and Long (1993), acceptable model fit indices were pre-specified. Specifically, indices of absolute fit, indices of relative fit and parsimony-adjusted fit indices were used to test model fit. The overall chi square test of model fit was examined and statistically non-significant chi square values (indicated by a Bollen-Stine corrected $p$ value greater than .05) indicated good model fit. The Comparative Fit Index (CFI) was examined and values of .95 or greater was used to define good model fit. The Goodness of Fit Index (GFI) was examined and values of .90 or greater indicated a good model fit. The Root Mean Square Error of Approximation (RMSEA) was examined; values less than 0.06 indicated a good model fit. Finally, the $p$ value for Close fit test was examined and values that were statistically non-significant (greater than .05) indicated a good model fit. In addition to the global fit indices, more focused tests of fit were examined. Modification indices of notable size (values of 4.0 or greater) were evaluated to see if there were any conceptual rationales for modifying the model. Additionally, standardized residual values were evaluated. Any values falling outside of the range of -2.0 and 2.0 were considered points of stress in the model and sources of ill fit.

The fit of the model in Figure 4 was evaluated with AMOS 16.0 using the sample covariance matrix as input and a maximum likelihood solution. Based on the criteria specified, the model fit was good. Therefore, hypotheses were investigated by interpreting individual paths in the full model, and are described below. 
Hypothesis 1. To test the relationship of the emotional functioning variable to the parent responsiveness variable, a direct path was specified from the emotional functioning variable to the mean parent responsiveness variable. The path was not significant. However, supplemental analyses were conducted to assess the associations between the parent emotional functioning subscales and the parent responsiveness variable. One important association was found. Parents' interpersonal functioning was positively correlated with parents' responsiveness $(r=.36, p<.05)$.

Hypothesis 2. To test the relationship of the parent responsiveness variable to both internalizing and externalizing child behavior problem variables, direct paths were specified from the parent responsiveness variable to both internalizing and externalizing behavior variables. The paths were not significant. Supplemental analyses also failed to generate any significant associations.

Hypothesis 3. To test the relationship of the overall emotional functioning variable to both the internalizing and externalizing behavior problem variables, direct paths were specified from the emotional functioning variable to both internalizing and externalizing behavior variables. As shown in Fig. 4, parameter estimates among factors indicate a negative relationship of parent emotional functioning to the child internalizing behaviors factor, accounting for more than $21 \%$ of its variance. The path from emotional functioning to child externalizing behaviors was not significant. Supplemental analyses were conducted to assess the associations between the parent emotional functioning subscales, including the total scale, and the child psychological adjustment subscales. Several important associations were found, in anticipated directions. Parents' intrapersonal functioning was negatively correlated with children's somatic complaints 
$(r=-.32, p<.05)$ and social problems score $(r=-.28, p<.05)$. Parents' stress management ability was negatively correlated with children’s anxious/depressed behaviors $(r=-.32, p<.05)$, somatic complaints $(r=-.30, p<.05)$, and overall internalizing behavior problems $(r=-.29, p<.05)$. Parents’ general mood was negatively correlated with children’s somatic complaints $(r=-.32, p<.05)$, social problems $(r=-.27, p<.05)$, and overall internalizing behavior problems $(r=-.28, p<.05)$

In the final stage of analyses, the goal was to determine whether parent emotional functioning impacted child behavior problems, mediated by parent responsiveness to child bids for interaction. A partial mediation model was specified that included an endogenous mediating latent variable, parent responsiveness. The exogenous predictor was the emotional functioning variable, and the internalizing and externalizing behavior problems variables were the dependent variables in this model. Direct paths were included between parent emotional functioning and both internalizing and externalizing child behavior problems, as well as indirect effects of emotional functioning, through mean parent responsiveness, on child internalizing and externalizing behavior problems. The specified mediation assumed that more positive parent emotional functioning should be associated with more parent responsiveness during interaction which, in turn, should be associated with lower levels of child internalizing and externalizing behavior problems. As noted previously, this model (see Fig. 4) provided a good fit to the data $(\mathrm{CMIN}=.05, \mathrm{CFI}=1.00, \mathrm{RMSEA}=.00, \mathrm{PCLOSE}=.84)$, accounting for $1 \%$ of the variance of parent responsiveness, $21 \%$ of the variance of internalizing behavior problems, and 3\% of the variance of externalizing behavior problems. Despite the fact 
that the model had good fit, the only significant path coefficient was the path from parent emotional functioning to child internalizing behavior. The paths from parent emotional functioning to both parent responsiveness and externalizing child behavior problems were not significant, nor were the paths from parent responsiveness to both internalizing and externalizing child behavior problems. Hence, the mediation hypothesis was not supported. 


\section{CHAPTER V \\ DISCUSSION}

The purpose of this study was to gain a greater understanding of the factors contributing to child adjustment by examining the influence of parent emotional functioning and parent responsiveness to child bids for interaction. The results of this exploratory study extended previous research, and helped to illuminate the complex relationships among key factors that should be examined in order to better understand what leads to children's psychological adjustment problems, or lack thereof. A strength of this study was the inclusion of a diverse sample, which improved upon the limitation of homogenous samples noted in previous attachment-related research.

Relationship of Emotional Functioning to Parent Responsiveness. The first aim of this study was to examine the relationship between parent emotional functioning and parent responsiveness to child bids. Previous research shows that poorly-adjusted mothers show marked differences in their interaction with, and responsiveness to, their children (Campbell, Cohn, \& Myers, 1995; Carter et al., 2001; DeMulder \& RadkeYarrow, 1991; Godman \& Gotlib, 2002), but the specific abnormal behaviors of such parents that cause them to interact differently have not been well-studied. Therefore, this study sought to delineate the specific emotional characteristics that affect parents' responsiveness to their children's bids for interaction. While overall emotional functioning did not predict parent responsiveness, more specific features of the relationship were supported. Consistent with the hypothesis, parents with higher interpersonal functioning were more responsive to their children's bids for interaction. Results are consistent with the premise that interpersonal functioning involves the ability 
to accurately perceive and respond to others (Bar-On, 1999), an ability that is necessary for sensitive attunement and responsiveness.

Relationship of Parent Responsiveness to Child Psychological Adjustment. The second aim of this study was to examine the relationship between parent responsiveness to child bids and child internalizing and externalizing behavior problems. Research shows that children with less responsive caregivers have higher rates of insecure attachment (Campbell, Cohn, Myers, Ross, \& Flanagan, 1993), which is associated with future psychological and behavior problems (Easterbrooks, Davidson, \& Chazin, 1993). However, in this study the hypothesis was not supported. (This result will be discussed below in the context of the whole model.)

Relationship of Emotional Functioning to Child Psychological Adjustment. The final aim of this study was to examine the relationship between parent emotional functioning and child internalizing and externalizing behavior problems. Additionally, the mediating role of parent responsiveness to child bids in this relationship was assessed. There is much empirical support for the fact that children of poorly-adjusted mothers are at increased risk for future psychopathology, and evidence suggests that early attachment insecurity may play a contributing role (Toth, Rogosch, Manly, \& Cicchetti, 2006). This study sought to investigate the effect of parent emotional functioning, operationalized as an indicator of the IWM, on child psychological adjustment, through parent responsiveness to child bids for interaction.

Consistent with the hypothesis, results indicated that parent emotional functioning does predict child internalizing problems. Specifically, as parents' overall emotional functioning increases by one unit, child internalizing behaviors decrease by .09 units. 
Equivalently, as parent emotional functioning goes up one standard deviation, child internalizing problems will go down .34 standard deviations.

A closer look at the subscale level revealed more specific findings. Parents who reported better intrapersonal functioning had children with fewer somatic complaints. This is consistent with the idea that somatic complaints occur when emotional stresses are experienced and communicated in the form of physical discomfort or illness (Lipowski, 1988); one interpretation of this finding that is consistent with clinical theory would be that mothers with poorer stress management skills convey that stress to their child, who then experiences and expresses somatic complaints (Steele, Dreyer, \& Phipps, 2004). Parents' emotional functioning was also associated with children's social problems. Since parents with emotional disturbance have impaired interaction with their children (Carter et al., 2001), the children may learn maladaptive interaction strategies and therefore suffer interpersonally, or socially. Parents who are effectively able to manage stress and anger tend to have children with fewer internalizing behaviors, specifically, anxious and depressed behaviors and somatic complaints. Such parents model adaptive coping strategies for dealing with problems and stress rather than succumbing to emotion-focused coping which can lead to somatic symptoms, anxiety or depression when stress levels are high. Similarly, parents who report better moods most of the time have children with fewer internalizing problems such as somatic complaints and fewer social problems. This is consistent with literature that shows that more positive affect, which is present during good moods, likely results in more positive child

affect, which s known to be associated with peer acceptance (Sroufe, Schork, Motti, 
Lawroski, \& LaFreniere, 1984).

Mediation Model: Relationship of Emotional Functioning to Child Psychological Adjustment, Mediated by Parent-Child Interaction. Parent responsiveness was hypothesized to mediate the relationship between parents' emotional functioning and children's psychological adjustment but the hypothesis was not supported in this study. However, when considering all the information gathered from this research, it becomes evident that there are complex processes involved in linking the IWM to specific behavioral manifestations in parent-child interaction, and these would best be investigated in the context of an ongoing comprehensive research program (e.g., Beebe \& Lachmann, 2005; Fogel, 1993; Jaffe, Beebe, Feldstein, Brown, \& Jasnow, 2001). While there is much research examining attachment processes, including parent-child interaction, during the infant years, a primary purpose of this study was to expand literature by studying the processes in school-aged children. The interaction between parents and infants might be considered more parsimonious compared to older children, as there are limited exchanges that can occur due to the developmental immaturity of the infant (see Tronic, Ricks, \& Cohn, 1992). Therefore, while this project takes a step in the right direction by attempting to explore the complex processes involved in attachment through parents' emotional functioning, parents' responsiveness to children's bids for interaction, and child psychological adjustment, there is much work left to be done.

Parents' IWM are known to shape their interaction with their children and impact psychological adjustment (Bowlby, 1973). Past studies have measured the nonconscious IWM through self-report measures or state of mind when discussing early experiences whereas this study sought to examine a, concrete expression of the IWM through 
everyday emotional functioning. The EQ measures how one responds to self and others in emotionally charged interactions and hence has implications for how an adult functions in family situations (specifically, how they interact with, and attune to, their children). Because the EQ-i identifies specific behavioral tendencies that may be amenable to cognitive behavioral intervention while it was also linked with specific aspects of child adjustment, it may be especially helpful for prevention or intervention programs targeting parents. In contrast, previous research purporting to measure the parent's IWM implicates intrapsychic tendencies that are thought to be amenable primarily through long-term psychotherapeutic intervention. Future research could investigate whether or not improving parent "emotional intelligence" (which is argued to be a characteristic that can be “raised”- e.g., Mayer \& Salovey, 1997) results in improved parent responsiveness, improved child adjustment, or both. If so, it might represent an efficacious strategy for ameliorating the burden of emotional suffering that many children endure.

\section{Limitations and Directions for Future Research}

Certain methodological limitations to this research should be noted. Of particular importance is the notion that the proposed model is almost certainly incomplete. The relatively small about of variance explained by several of the model paths suggests that processes besides than those included in the model may be impacting parents' responsiveness and its effect on children. Additionally, this study tested a model between general constructs which are comprised of many subscales that were not individually tested in this study. Supplemental analyses revealed associations between specific features of parent emotional functioning and child internalizing and externalizing problems. Future research should test models with more specific aspects of parent 
emotional functioning and child psychological adjustment. Also, while this study incorporated both observational and parent self-report measures, incorporating measures from various sources (e.g., child, teacher, or therapist report) could provide additional perspectives into the processes contributing to these dynamic concepts.

\section{Conceptual and Clinical Implications}

Despite the previously noted limitations, the results of this study suggest several important conceptual and clinical implications for both children and parents. Overall, the present study adds to our understanding of how parent characteristics predict child psychological adjustment. The results were consistent with the notion that conceptualizing emotional intelligence might be a concrete, everyday manifestation of the nonconscious attachment IWM through which parents impact their children's adjustment (and presumably, their IWM). The pattern of support for the hypotheses illustrates the need for more research on parent emotional functioning, attachment related processes such as parent-child interaction quality, and child outcomes.

As noted above, he results of this study also suggest potential points for therapeutic intervention, i.e., teaching parents how to manage their own emotions, and interact optimally with children. This study revealed that there are certain features of parent-child interaction, particularly parents' responsiveness to children’s bids for interaction, can be detected in a routine parent/child play task assessment appear to be promising indicators of parent adjustment problems (i.e., interpersonal functioning). Thus, future research might examine the feasibility of interventions that educate parents on the importance of interaction with their children and moreover, their responsiveness to their children while interacting. Another point of intervention may be the development of 
early detection techniques to assess parent emotional functioning which can then be targeted before it affects children in more chronic and profound ways.

In conclusion, the current investigation represents an important step in illuminating the complex relationships among parent emotional functioning, parents' responsiveness to their children during interaction, and child psychological adjustment. This research makes empirical and theoretical contributions that may to facilitate more efficacious prevention and intervention efforts, specifically those geared toward reducing child psychopathology(Beg, Casey, \& Saunders, 2007; NMHA, 2007). As rates of child psychopathology continue to increase in the United States, the need for identifying mechanisms whereby positive child adjustment is fostered and poor adjustment is prevented or ameliorated is even more imperative. 
Table 1

Demographic Characteristics of Participants $(N=97)$

\begin{tabular}{lcc} 
Variable & $n$ & $\%$ \\
\hline Gender & 62 & 63.9 \\
Male & 35 & 36.1 \\
Female & & \\
Ethnicity & & \\
Hispanic & 69 & 71.1 \\
White & 28 & 28.9
\end{tabular}

Current Marital Status

Married

$72 \quad 75.0$

Divorced

$11 \quad 11.5$

Single

$10 \quad 10.4$

Separated

$3 \quad 3.1$

Mother's Education

Some High School

$4 \quad 4.6$

High School

$7 \quad 8.0$

Some College

$33 \quad 37.9$

College

$35 \quad 40.2$

Advanced Degree

$\begin{array}{ll}8 & 9.2\end{array}$ 
Table 2

Pearson Correlations for all EQ Variables

\begin{tabular}{|c|c|c|c|c|c|c|}
\hline Measure & 1 & 2 & 3 & 4 & 5 & 6 \\
\hline 1. Intrapersonal & -- & & & & & \\
\hline 2. Interpersonal & $.55 * *$ & -- & & & & \\
\hline 3. Stress Management & $.36 * *$ & $.54 * *$ & -- & & & \\
\hline 4. Adaptability & .48 & $.70 * *$ & .61 & -- & & \\
\hline 5. Mood & $.75 * *$ & $.66 * *$ & $.67 * *$ & $.71 * *$ & -- & \\
\hline 6. Total EQ & $.77^{* *}$ & $.81^{* *}$ & $.77 * *$ & $.80 * *$ & $.93 * *$ & -- \\
\hline
\end{tabular}


Table 3

Pearson Correlations for CBCL Syndrome Scale Variables

\begin{tabular}{|c|c|c|c|c|c|c|c|c|}
\hline Measure & 1 & 2 & 3 & 4 & 5 & 6 & 7 & 8 \\
\hline 1. Anx/Depr & -- & & & & & & & \\
\hline 2. With/Dep & $.57 * *$ & -- & & & & & & \\
\hline 3. Somatic & $.50 * *$ & $.30 * *$ & -- & & & & & \\
\hline 4. Internalizing & $.88 * *$ & $.77 * *$ & $.67 * *$ & -- & & & & \\
\hline 5. Social Prob & $.63 * *$ & $.44 * *$ & $.61^{* *}$ & $.69 * *$ & -- & & & \\
\hline 6. Thought Prob & $.46^{* *}$ & $.30 * *$ & $.33 * *$ & $.46^{* *}$ & $.37 * *$ & -- & & \\
\hline 7. Attention Prob & $.37 * *$ & $.22 * *$ & $.36 * *$ & $.35 *$ & $.53 * *$ & $.56 * *$ & -- & \\
\hline 8. Externalizing & $.32 * *$ & $.42 * *$ & .12 & $.46 * *$ & $.49 * *$ & $.46^{* *}$ & $.42 * *$ & - \\
\hline
\end{tabular}

Note. ${ }^{*} p<.05 .{ }^{* *} p<.01$ 
Table 4

Descriptive Statistics for all Model Variables

\begin{tabular}{|c|c|c|c|c|c|c|}
\hline Variable & $M$ & SD & Min & $\operatorname{Max}$ & Skewness & Kurtosis \\
\hline \multicolumn{7}{|l|}{ Parent EQ } \\
\hline Intrapersonal & 36.47 & 6.76 & 19 & 50 & -.33 & .10 \\
\hline Interpersonal & 42.14 & 5.94 & 16 & 50 & -1.86 & 6.50 \\
\hline Stress Management & 28.04 & 6.57 & 11 & 40 & -.45 & .30 \\
\hline Adaptability & 25.35 & 4.05 & 17 & 33 & -.10 & -.93 \\
\hline General Mood & 37.76 & 7.14 & 18 & 49 & -.77 & .13 \\
\hline Total EQ & 186.14 & 27.56 & 97 & 238 & -.60 & .95 \\
\hline \multicolumn{7}{|l|}{ Observed Parent Behavior } \\
\hline Responsiveness & 2.43 & .56 & .00 & 3 & -.62 & -.36 \\
\hline \multicolumn{7}{|l|}{$\underline{\text { Child Adjustment }}$} \\
\hline Anxious/Depressed & 4.90 & 4.20 & .00 & 22 & 1.33 & 2.35 \\
\hline Withdrawn/Depressed & 2.47 & 2.30 & .00 & 10 & 1.07 & .62 \\
\hline Somatic Complaints & 2.51 & 2.27 & .00 & 10 & 1.09 & .84 \\
\hline Social Problems & 4.25 & 3.67 & .00 & 17 & 1.08 & .91 \\
\hline Thought Problems & 3.39 & 3.48 & .00 & 16 & 1.80 & 3.61 \\
\hline Attention Problems & 6.22 & 4.88 & .00 & 20 & .80 & .00 \\
\hline Internalizing & 10.53 & 7.29 & .00 & 37 & .96 & 1.01 \\
\hline Externalizing & 13.46 & 8.67 & .00 & 39 & .84 & .13 \\
\hline
\end{tabular}


Figure 4. Standardized Coefficients for Study Model. CFI = comparative fit index; GFI goodness of fit; RMSEA = root mean squared error of approximation; PCLOSE = pvalue of a test on RMSEA. Latent constructs are shown in ellipses, and observed variables are shown in rectangles. - Intern = internalizing behavior problems; Extern = externalizing behavior problems. Values presented in parentheses are standardized coefficients. ${ }^{*} p<.05$

$\begin{array}{lll}\mathrm{X}^{2}(2) & = & 2.47 \\ \mathrm{CFI} & = & .98 \\ \mathrm{RMSEA} & = & .05 \\ \mathrm{PCLOSE} & = & .37\end{array}$

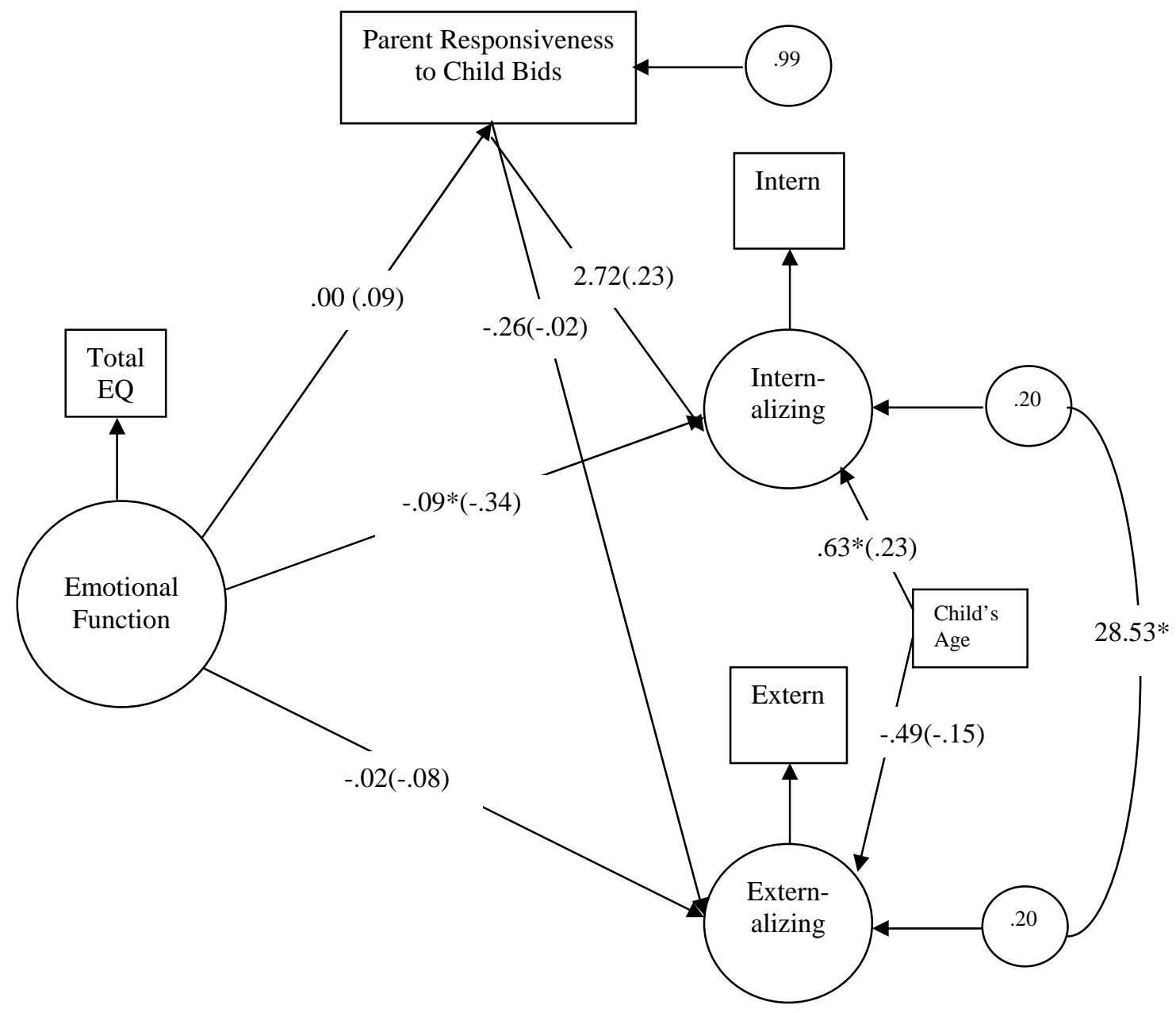




\section{REFERENCES}

Abidin, R. (1990). Parenting stress index manual. Charlottesville, VA: Pediatric Psychology Press.

Achenbach, T. \& Edelbrock, C. (1987). Child behavior checklist. Burlington, VT: University of Vermont, Department of Psychiatry.

Achenbach, T. \& Rescorla, L. (2000). Manual for the ASEBA preschool forms \& profiles. Burlington, VT: University of Vermont, Research Center for Children, Youth, \& Families.

Ainsworth, M. (1963). The development of infant-mother interaction among the Ganda. In B. Foss (Ed.), Determinants of infant behavior (Vol. 2, pp. 67-112). London: Methuen.

Ainsworth, M. (1967), Infancy in Uganda: Infant care and the growth of love. Baltimore: Johns Hopkins University Press,

Ainsworth, M., Blehar, M., Waters, E., \& Wall, S. (1978). Patterns of attachment: A psychological study of the strange situation. Hillsdale, NJ: Erlbaum.

Ainsworth, M., Bell, S., \& Stayton, D. (1971). Individual differences in strange situation behavior of one year olds. In. H. Schaffer (Ed.), The origins of human social relations. London: Academic Press.

Ainsworth, M., Bell, S., \& Strayton, D. (1974). Infant-mother attachment and social development: Socialization as a product of reciprocal responsiveness to signals. In M. Richards (Ed.). The introduction of the child into a social world. London: Cambridge University Press.

Ainsworth, M. (1975). Infancy in Uganda. John Hopkins University Press.

American Psychiatric Association. (2000). Diagnostic and statistical manual of mental disorders (4th ed., revised). Washington, DC: Author.

Bar-On, R. (1999). EQ-i: BarOn emotional quotient inventory technical manual. New York: Multi-Health Systems Inc.

Bar-On, R. (2002). EQ-I: Bar-On emotional quotient inventory technical manual. Toronto, Canada: Multi-Health Systems.

Bar-On, R. (2006). The Bar-On model of emotional-social intelligence (ESI). Psicothema, 18, 13- 25. 
Barnard, K.E., \& Kelly, J.F. (1990). Assessment of parent-child interaction. In J.P. Shonkoff \& S.J. Meisels (Eds.), Handbook of early childhood intervention (pp. 278-302). New York: Cambridge University Press.

Beebe, B., \& Lachmann, F. M. (2001). Infant research and adult treatment: Co-constructing interactions. New York: The Analytic Press.

Beg, M., Casey, J., \& Saunders, C. (2007). A typology of behavior problems in preschool children. Assessment, 14(2), 111-128.

Bell, S. M, \& Ainsworth, M. D. S. (1972). Infant crying and maternal responsiveness. Child Development, 43, 1171-1190.

Belsky, J. (1999a). Interactional and contextual determinants of attachment security. In J. Cassidy \& P. Shaver (Eds.), Handbook of Attachment: Theory, Research, and Clinical Applications (pp. 249-264). New York: Guilford Press.

Belsky, J., Lerner, R., \& Spanier, G. (1984). The Child in the Family. Reading, MA: Addison-Wesley.

Belsky, J., Rovine, M., \& Taylor, I. (1984). The Pennsylvania Infant arid Family Development Project, II: Origins of individual differences in infant-mother attachment: Maternal and infant contributions, Child Development, 55, 706-717.

Belsky, J., Rosenberger, K., \& Crnic, K. (1995). The origins of attachment security: "Classical" and contextual determinants. In S. Goldberg, R. Muir, \& J. Kerr (Eds.), Attachment theory: Social, developmental, and clinical perspectives (pp.153-184). Hillsdale, NJ: Analytic Press.

Berlin, L. \& Cassidy, J. (2000). Parenting and attachment. In J. Osofsky \& H. Fitzgerald (Eds.), WAIMH Handbook of Mental Health: Vol 3. Parenting and child care (pp. 137-170). New York: Wiley.

Berlin, L., Ziv, Y., Amaya-Jackson, L., \& Greenberg, M. (2005). Enhancing early attachments: Theory, research, intervention, and policy. New York: Guilford Press.

Biederman, J., Monuteaux, M. C., Greene, R. W., Braaten, E., \& Doyle, A. E., \& Faraone, S. V. (2001). Long-term stability of the Child Behavior Checklist in a clinical sample of youth with attention deficit hyperactivity disorder. Journal of Clinical Child Psychology, 30(4), 492-502.

Birmaher, B., Ryan, N. D., Williamson, D. E., Brent, D. A., Kaufman, J., Dahl R. E., Perel, J., \& Nelson, B. (1996). Childhood and adolescent depression: A review of 
the past 10 years. Journal of the American Academy of Child and Adolescent Psychiatry, 35, 1427-1439.

Blehar, M., Lieberman, A., \& Ainsworth, M. (1977). Early face-to-face interaction and its relation to later infant-mother attachment. Child Development, 48, 182-194.

Bollen, K. \& Long, J. (1993). Testing structural equation models. Beverly Hills, CA: Sage.

Bowlby, J. (1951). Maternal care and mental health. World Health Organization Monograph (Serial No. 2).

Bowlby, J. (1969). Attachment and loss (Vol. 1: Attachment). New York: Basic Books.

Bowlby, J. (1973). Attachment and loss (Vol. 2: Separation). New York: Basic Books.

Bowlby, J. (1980). Attachment and loss (Vol. 3: Loss). New York: Basic Books.

Bowlby, J. (1982). Attachment and loss, Vol 1. Attachment (2 ${ }^{\text {nd }}$ ed.). New York: Basic Books.

Bowlby, J. (1988). A secure base. New York: Basic Books.

Bretherton, I. (1992). The origins of attachment theory: John Bowlby and Mary Ainsworth. Developmental Psychology, 28, 759-775.

Burns, R.A., Lock, T., Edwards,, Katona, C.L.E., Harrison, D.A., Robertson, M.M., Nairac, B., Abou-Saleh, M.T., 1995. Predictors of response to amine-specific antidepressants. Journal of Affective Disorders, 35, 97-106.

Campbell, S. B., Cohn, J. F., \& Myers, T. (1995). Depression in first-time mothers: Mother-infant interaction and depression chronicity. Developmental Psychology, 31,349-357.

Campbell, S.B., Cohn, J.F., Meyers, T.A., Ross, S., \& Flanagan, C. (1993). Chronicity of maternal depression and mother-infant interaction. In D. Teti (Chair), Depressed mothers and their children: Individual differences in motherchild outcome. Symposium conducted at the meeting of the Society for Research in Child Development, New Orleans, LA.

Carter, A., Garrity-Rokous, F. E., Chazen-Cohen, R., Little, C., \& Briggs-Gowen, M. (2001). Maternal depression and comorbidity: Predicting early parenting, 
attachment security and toddler social-emotional problems and competencies. Journal of the American Academy of Child and Adolescent Psychiatry, 40(1), 1826.

Cicchetti D, Rogosch FA, Toth SL (1998). Maternal depressive disorders and contextual risk: contributions to the development of attachment insecurity and behavior problems. Developmental Psychopathology, 10, 283-300.

Cicchetti, D. \& Toth, S. (1995). Developmental Psychopathology and Disorders of Affect. In D. Cicchetti and D. Cohen (Eds.), Developmental psychopathology, Volume 2: Risk, disorder, and adaptation (pp. 369-420). New York: John Wiley \& Sons, Inc.

Clark, K. E.,\&Ladd, G.W. (2000). Connectedness and autonomy support in parent-child relationships: Links to children's socioemotional orientation and peer relationships. Developmental Psychology, 36, 485-498.

Collins, N., \& Read, S. (1994). Cognitive representations of attachment: The structure and function of working models. In K. Bartholomew \& D. Perlman (Eds.), Attachment processes in adulthood: Advances in personal relationships (Vol. 5, pp. 53-90). London: Kingsley.

Criss, M., Shaw, D. S., \& Ingoldsby, E. (2003). Mother-son positive synchrony in middle childhood: Relation to antisocial behavior. Social Development, 12, 379400 .

Crowell, J. A., \& Feldman, S. S. (1988). Mothers' internal models of relationships and children's behavioral and developmental status: A study of mother-child interaction. Child Development, 59, 1273-1285.

Cummings, E. M., \& Cicchetti, D. (1990). Attachment, depression, and the transmission of depression. In M. T. Greenberg, D. Cicchetti, \& E. M. Cummings (Eds.), Attachment during the preschool years (pp. 339-372). Chicago: University of Chicago Press.

Cummings, E. \& Davies, P. (2006). Maternal Depression and Child Development. Journal of Child Psychology and Psychiatry, 35, 73-122.

Cummings, E.M., Davies, P.T., \& Campbell, S.B. (2000). Developmental psychopathology and family process. New York: The Guilford Press.

Dadds, M. (1995), Passionate enquiry and school development: A story about teacher action research, London: Falmer Press.

Darwin, C. (1872). On the Origin of Species, (6 $6^{\text {th }}$ ed.). John Murray, London. 
Derogatis, L. R., \& Melisaratos, N. (1983). The Brief Symptom Inventory: An introductory report. Psychological Medicine, 13, 595 - 605.

DeMulder, E. K., \& Radke-Yarrow, M. (1991). Attachment with affectively ill and well mothers: Concurrent behavioral correlates. Development and Psychopathology, 3, 227-242.

De Wolff, M. \& Van IJzendoorn, M. (1997). Sensitivity and attachment: A meta-analysis on parental antecedents of infant attachment. Child Development, 66, 571-591.

Diamond, D., \& Blatt, S. J. (1994). Internal working models and the representational world in attachment and psychoanalytic theories. In M. B. Sperling \&W. H. Berman (Eds.), Attachment in adults: Clinical and developmental perspectives (pp. 72-97). New York: Guilford.

Easterbrooks, M.A., Davidson, C. E., and Chazan, R.Z. (1993). Psychosocial risk, attachment, and behavior problems among school-aged children. Development and Psychopathology, 5, 389-420.

Egeland, B. \& Farber, E. (1984). Infant-Mother Attachment: Factors related to its development and changes over time. Child Development, 55, 753-771.

Egeland, B., \& Carlson, E. (2004). Attachment and psychopathology. In L. Atkinson (Ed.), Clinical Applications of Attachment. (pp.27-48). Mahwah, NJ: Lawrence Erlbaum Associates, Inc.

Eiden, R., Teti, D., \& Corns, K. (1995). Maternal working models of attachment, marital adjustment, and the parent-child relationship. Child Development, 66, 1504-1518.

Elicker, J., Englund, M., \& Sroufe, L. (1992). Predicting peer competence and peer relationships in childhood from early parent-child relationships. In. R. Parke \& G. Ladds (Eds.), Family-peer relationships: Modes of linkage (pp. 77-106). Hillsdale, NJ: Erlbaum.

Erickson, M., Egeland, B., \& Sroufe, L. (1985). The relationship between quality of attachment and behavior problems in preschool in a high risk sample. In I. Bretherton \& E. Waters (Eds.), Growing points in attachment theory and research. Monographs of the Society for Research in Child Development, 50, 147-186.

Feldman, R., Greenbaum, C. W., \& Yirmiya, N. (1999). Mother-infant affect synchrony as an antecedent of the emergence of self-control. Developmental Psychology, 35, 223-231. 
Fogel, A. (1993). Developing through relationships. Chicago: University of Chicago Press.

Goodman, S.H., \& Gotlib, I.H. (2002). Introduction. In S.H. Goodman \& I.H. Gotlib (Eds.), Children of depressed parents: Mechanisms of risk and implications for treatment (pp. 3-9). Washington, DC: American Psychological Association.

Grossmann, K., Grossmann, K. E., Spangler, G., Suess, G., \& Unzner, L. (1985). Maternal sensitivity and newborns' orientation responses as related to quality of attachment in Northern Germany. In I. Bretherton \& E. Waters (Eds.), Growing points of attachment theory and research, Monographs of the Society for Research in Child Development, 50 (1-2, Serial No. 209).

Gunner, M. (1998). Quality of early care and buffering of neuroendocrine stress reactions: Potential effects on the developing human brain. Preventive Medicine, 27, 208-211.

Gunnar, M.R. (2000, November). Patterns of cortisol production in orphanage-reared children. Paper presented at the annual meeting of the International Society of Developmental Psychobiology, New Orleans, LA.

Harrist, A. W., \& Waugh, R. M. (2002). Dyadic synchrony: Its structure and function in children's development. Developmental Review, 22, 555-592.

Hoyle, R. H., \& Panter, A. T. (1995). Writing about structural equation models. In R. H. Hoyle (Ed.), Structural equation modeling (pp. 158-176). Thousand Oaks, CA: Sage.

Isabella, R., \& Belsky, J. (1991). Interactional synchrony and the origins of infant -mother attachment: A replication study. Child Development, 62, 373-384.

Isabella, R.A., Belsky, J., \& von Eye, A. (1989). The origins of infant-mother attachment: An examination of interactional synchrony during the infant's first year. Developmental Psychology, 25, 12-21.

Jaccard, J. and Wan, C. (1996). LISREL analyses of interaction effects in multiple regression. Newbury Park: Sage.

Jacobsen, T., \& Hofmann, V. (1997). Children's attachment representations: Longitudinal relations to school behavior and academic competency in middle childhood and adolescence. Developmental Psychology, 33, 703-710.

Jaffe, J., Beebe, F., Felstein, S., Crown, C., \& Jasnow, M. (2001). Rhythms of dialogue in infancy: Monograph of the Society for Research on Child Development. New York: Wiley Blackwell. 
Joreskog, K. \& Sorbom, D, (1996). Users manual for LISREL. Chicago: Scientific Software.

Karen, R. (1994). Becoming attached: First relationships and how they shape our capacity to love. New York: Oxford University Press.

Kerns, K. A. (1994). A developmental model of the relations between mother-child attachment and friendship. In R. Erber \& R. Gilmour (Eds.), Theoretical frameworks for personal relationships (pp. 129-156). Hillsdale, England: Lawrence Erlbaum Associates.

Kerns, K., Klepac, L. \& Cole, A. (1996). Peer relationships and preadolescents' perceptions of security in the child-mother relationship, Developmental Psychology, 32, 457-466.

Klein, R. B. (1998). Principles and practice of structural equation modeling. New York: Guilford.

Kochanska, G. (2001). Emotional development in children with different attachment histories: The first three years. Child Development, 72, 474-490.

Kochanska, G. (2002). Mutually responsive orientation between mothers and their young children: A context for the early development of conscience. Current Directions in Psychological Science, 11, 191-195.

Levy, K.N., Blatt, S.J. (1999). Attachment Theory and Psychoanalysis: Further differentiation within insecure attachment patterns. Psychoanalytic Inquiry, 19, 541-575.

Levitt, M.J. (1991). Attachment and close relationships: A life-span perspective. In J.L. Gewirtz \& W.M. Kurtines (Eds.), Intersections with attachment (pp. 183-205). Hilssdale, N.J.: L. Erbaum.

Levitt, M.J. (2005). Social relations in childhood and adolescence: The convoy model perspective. Human Development, 48, 28-47.

Levitt, M.J., Guacci-Franco, N., \& Levitt, J.L. (1993). Convoys of social support in childhood and early adolescence: Structure and function. Developmental Psychology, 29, 811-818.

Lindsey, E. W., Mize, J., \& Pettit, G. S. (1997). Mutuality in parent-child play: Consequences for children's peer competence. Journal of Social and Personal Relationships, 14, 523-538. 
Lipowski, Z. (1988). Somatization: The concept and its clinical application. American Journal of Psychiatry, 145, 1358-1368.

Lorenz, K. Z. (1935). Der Kumpan in der Umwelt des Vogels (The companion in the bird's world). Journal fur Ornithologie, 83, 137-213. (Abbreviated English translation published 1937 in Auk, 54, 245-273.)

Main, M. (1990). Cross-cultural studies of attachment organization: Recent studies, changing methodologies and the concept of conditional strategies. Human Development, 33, 48-61.

Main, M. \& Goldwyn, R. (1994). Adult Attachment Rating and Classification System, Manual in Draft: Version 6.0. Unpublished manuscript, University of California at Berkeley.

Main M., Kaplan, N., \& Cassidy, J. (1985). Security in infancy, childhood, and adulthood: A move to the level of representation. In I. Bretherton \& E, Waters (Eds.), Growing Points in Attachment Theory and Research. Monographs of the Society for Research in Child Development, 50(1-2, Serial No. 209), 66-104.

Maslin, C. A,, \& Bates, J. E. (1983). Precursors of anxious and secure attachments: A multivariate model at age 6 months. Paper presented at the biennial meeting of the Society for Research in Child Development, Detroit.

Mayer, J. \& Salovey, P. (1997). What is emotional intelligence? In P. Salovey \& D. Sluyter (Eds). Emotional development and emotional intelligence: Implications for educators (pp. 3-31). New York: Basic Books.

McConaughy, S.H., \& Achenbach, T.M., (2001). Manual for the Semistructured Clinical Interview for Children and Adolescents ( $2^{\text {nd }}$ edition). VT: University of Vermont, Research Center for Children, Youth \& Families.

Moos, R. H. \& Moos, B. S. (1986). Family Environment Scale Manual ( $2^{\text {nd }}$ ed.) Palo Alto, CA: Consulting Psychologists Press.

National Mental Health Association (2007). Did You Know? Retrieved September 10, 2007, from http://www1.nmha.org/infoctr/didyou.cfm

Olson, D.H., Portner, J., \& Lavee, Y. (1985). Family Adaptability and Cohesion Evaluation Scales. MN: University of Minnesota.

Moos, R. H. \& Moos, B. S. (1986). Family Environment Scale Manual ( $2^{\text {nd }}$ ed.) Palo Alto, CA: Consulting Psychologists Press. 
Pederson, D., Gleason, K., Moran, G., \& Bento, S. (1998). Maternal attachment representations, maternal sensitivity, and the infant-mother attachment relationship. Developmental Psychology, 34, 925-933.

Pederson, D. R., Moran, G., Sitko, C., Campbell, K., Ghesquire, K., \& Acton, H. (1990). Maternal sensitivity and the security of infant mother attachment: A Qsort study. Child Development, 61,1974-1983.

Propper, C. \& Moore, G.A. (2006). The influence of parenting on infant emotionality: A multi-level psychobiological perspective. Developmental Review, 26, $427-460$.

Roberts, R., Zeidner, M. \& Matthews, G. (2001). "Does emotional intelligence meet traditional standards for an intelligence? Some new data and conclusions", Emotion, 1, 196-231.

Russo, J.B. \& Owens, R.E. (1982). The development of an objective observation tool for parent-child interaction. Journal of Speech and Hearing Disorders, 47, 165173.

Salovery, P. \& Mayer, J. (1990). “Emotional Intelligence”, Imagination, Cognition, and Personality, 9, 185-211.

Sanders, M.R., Dadds, M.R., Johnston, B.M., \& Cash, R. (1992). Childhood depression and Conduct Disorder: I. Behavioral, affective, and cognitive aspects of family problem solving interactions. Journal of Abnormal Psychology, 101, 495-504.

Schaffer, H, R., \& Emerson, P. F. (1964). The development of social attachments in infancy. Monographs of the Society for Research in Child Development, 29 (Serial No. 94).

Schneider, B. H., Atkinson, L., \& Tardif, C. (2001). Child-parent attachment and children's peer relations: A quantitative review. Developmental Psychology, 37, 86-100.

Seligman, M. E. P., Rashid, T., \& Parks, A. C. (2006). Positive psychotherapy. American Psychologist 61, 774-778.

Shaffer, D., Fischer, P., Dulcan, M. Davies, M., Piacentini, J., Schwab-Stone, M., Lahey, B. B., Bourdon, K., Jensen, P., Bird, H. R., Canino, G., \& Regier, D. (1996). The NIMH Diagnostic Interview Schedule for Children (DISC-2): Description, acceptability, prevalences, and performance in the MECA Study. Journal of the American Academy of Child and Adolescent Psychiatry, 35, 865877. 
Shaver, P. \& Mikulincer, M. (2005). Attachment theory and research: Resurrection of the psychodynamic approach to personality. Journal of Research in Personality, 39, 22-45.

Sheeber, L. B. \& Johnson, J. H. (1994). Evaluation of a temperament-focused, parent- training program. Journal of Clinical Child Psychology, 23(3), 249-259.

Shrout, P. E. \& Bolger, N. 2002. Mediation in experimental and nonexperimental studies: New procedures and recommendations. Psychological Methods, 7, 422445.

Skuban, E. M., Shaw, D. S., Gardner, F., Supplee, L. H., \& Nichols, S. R. (2006). The correlates of dyadic synchrony in high-risk, low-income toddler boys. Infant Behavior \& Development, 29(3), 423-434.

Slade, A., \& Aber, J. L. (1992). Attachments, drives and development: Conflicts and convergencies in theory. In J. W. Barron, M. N. Eagle, \& D. L. Wolitzky (Eds.), Interface of Psychoanalysis and Psychology, 154-185. Washington, DC: American Psychological Association.

Smith, P., \& Pederson, D. (1988). Maternal sensitivity and patterns of infant-mother attachment. Child Development, 50, 971-975.

Sroufe, A., Carlson E., Levy, A., \& Egeland, B. (1999) Implications of attachment theory for developmental psychology. Development \& Psychopathology, 11, 113.

Sroufe, L. A., \& Fleeson, J. (1986). Attachment and the construction of relationships. In W. W. Hartup and Z. Rubin (Eds.), Relationships and development (pp. 51-71). Hillsdale, NJ: Erlbaum.

Sroufe, Schork, Motti, Lawroski, \& LaFreniere. (1984)

St. Clair, M. \& Wigrin, J. (2004). Object Relations and Self Psychology: An Introduction ( $4^{\text {th }}$ Ed.) Monterey: Brooks-Cole.

Steele, R., Dreyer, M., \& Phipps, P. (2004). Patterns of maternal distress among children with cancer and their association with child emotional and somatic distress. Journal of Pediatric Psychology, 29, 507-517.

Surgeon General, (2000) Report on Mental Health, [Online] available: http://www.surgeongeneral.gov/library/mentalhealth/home.html 
Tarullo, E. (1994). Dialogues with preadolescents and adolescents: Mother-child interaction patterns in affectively ill and well dyads. Journal of Abnormal Child Psychology, 22, 33-51.

Toth, S. L., Rogosch, F. A., Manly, J. T., \& Cicchetti, D. (2006). The efficacy of toddler-parent psychotherapy to reorganize attachment in the young offspring of mothers with major depressive disorder: A randomized preventive trial. Journal of Consulting and Clinical Psychology, 74, 1006-1016.

Tronick, E., Ricks, M., and Cohn, J.F. (1982). Maternal and infant affective exchange: Patterns of adaptation. In T. Field and A. Fogel (Eds.), Emotion and interaction: Normal and high risk infants (pp. 83-100). Hillsdale, NJ: Erlbaum.

Tsujino, J. \& Oyama-Higa, M. (2007). The relationship between emotional intelligence of mothers and problem behavior in their young children: A longitudinal analysis. Journal of Prenatal and Perinatal Psychology and Health, 21, 215-229.

Van IJzendoorn, M. (1995). Adult attachment representations, parental responsiveness, and infant attachment: A meta-analysis on the predictive validity of the adult attachment interview. Psychological Bulletin, 117(3), 387-403.

Van IJzendoorn, M. H., Schuengel, C., \& Bakermans-Kranenburg, M. J. (1999). Disorganized attachment in early childhood: Meta-analysis of precursors, concomitants, and sequelae. Development and Psychopathology, 11, 225-249.

Waters, E., Wippman, J., \& Sroufe, L. (1979). Attachment, positive affect, and competence in the peer group: two studies in construct validation. Child Development, 50, 821-829.

Weinfield, N., Sroufe, L., Egeland, B., \& Carlson, E. (1999) The nature of individual differences in infant-caregiver attachment. In P. Shaver \& J. Cassidy (Eds.), Handbook of Attachment: Theory, Research, and Clinical Implications. New York: Guilford.

Wilcox, R. (2002). Understanding the practical advantages of modern ANOVA methods. Journal of Clinical Child \& Adolescent Psychology, 31(3), 399-412.

Wilcox, R. (1997). Introduction to robust estimation and hypothesis testing. San Diego: Academic Press.

Wilcox, R. (1999). Fundamentals of modern statistical methods. New York: Springer.

Wilcox, R. (2003). Applying contemporary statistical techniques. San Diego: Academic Press. 


\section{APPENDICES}


The Bar On EQ-i:s consists of statements that provide you with an opportunity to describe yourself by indicating the degree to which each statement is true to the way you feel, think or act most of the time and in most situations. There are five possible responses to each sentence.

\section{1-Very seldom or Not true of me; 2- Seldom true of me; 3- sometimes true of me; 4- Often true of me; 5- Very often true of me or True of me}

Read each statement and decide which one of the five responses best describes you. Mark your choices in the answer sheet by circling the number that corresponds to your answer. If a statement does not apply to you, respond in such a way that will give the best indication of how you would possibly feel, think, or act. Although some of the sentences may not give you all the information you would like to receive, choose the response that seems the best, even if you are not sure. There are no "right" or "wrong" answers and no "good" or "bad" choices. Answer openly and honestly by indicating how you actually are and not how you would like to be or how you would like to be seen. There is no time limit, but work quickly and make sure you consider and respond to every statement.

\begin{tabular}{|c|c|c|c|c|c|}
\hline & $\begin{array}{l}\text { Very } \\
\text { seldom } \\
\text { Or not } \\
\text { true } \\
\text { Of me }\end{array}$ & $\begin{array}{l}\text { Seldo } \\
\text { m } \\
\text { True } \\
\text { Of me }\end{array}$ & $\begin{array}{l}\text { Sometim } \\
\text { es } \\
\text { True } \\
\text { Of me }\end{array}$ & $\begin{array}{l}\text { Often } \\
\text { True } \\
\text { of me }\end{array}$ & $\begin{array}{l}\text { Very } \\
\text { often true } \\
\text { of me or } \\
\text { True of } \\
\text { me }\end{array}$ \\
\hline $\begin{array}{l}\text { 1. I'm a fairly cheerful } \\
\text { person }\end{array}$ & 1 & 2 & 3 & 4 & 5 \\
\hline 2. I like helping people. & 1 & 2 & 3 & 4 & 5 \\
\hline $\begin{array}{l}\text { 3. I'm unable to express } \\
\text { my ideas to others }\end{array}$ & 1 & 2 & 3 & 4 & 5 \\
\hline $\begin{array}{l}\text { 4. It is a problem } \\
\text { controlling my anger. }\end{array}$ & 1 & 2 & 3 & 4 & 5 \\
\hline $\begin{array}{l}\text { 5. My approach in } \\
\text { overcoming difficulties } \\
\text { is to move step by step. }\end{array}$ & 1 & 2 & 3 & 4 & 5 \\
\hline $\begin{array}{l}\text { 6.I don't do anything bad } \\
\text { in life. }\end{array}$ & 1 & 2 & 3 & 4 & 5 \\
\hline $\begin{array}{l}\text { 7. I feel sure of myself in } \\
\text { most situations. }\end{array}$ & 1 & 2 & 3 & 4 & 5 \\
\hline $\begin{array}{l}\text { 8. I'm unable to } \\
\text { understand the way other } \\
\text { people feel. }\end{array}$ & 1 & 2 & 3 & 4 & 5 \\
\hline $\begin{array}{l}\text { 9. I prefer others to make } \\
\text { decisions for me. }\end{array}$ & 1 & 2 & 3 & 4 & 5 \\
\hline 10. My impulsiveness & 1 & 2 & 3 & 4 & 5 \\
\hline
\end{tabular}




\begin{tabular}{|c|c|c|c|c|c|}
\hline $\begin{array}{l}\text { 11. I try to see things like } \\
\text { they really are, without } \\
\text { fantasizing or day } \\
\text { dreaming about them. }\end{array}$ & 1 & 2 & 3 & 4 & 5 \\
\hline 12. Nothing disturbs me. & 1 & 2 & 3 & 4 & 5 \\
\hline $\begin{array}{l}\text { 13.I believe that I can } \\
\text { stay on top of difficult } \\
\text { situations. }\end{array}$ & 1 & 2 & 3 & 4 & 5 \\
\hline $\begin{array}{l}\text { 14. I'm good at } \\
\text { understanding the way } \\
\text { other people feel. }\end{array}$ & 1 & 2 & 3 & 4 & 5 \\
\hline $\begin{array}{l}\text { 15. It's hard for me to } \\
\text { understand the way I } \\
\text { feel. }\end{array}$ & 1 & 2 & 3 & 4 & 5 \\
\hline $\begin{array}{l}\text { 16. I feel that it's hard } \\
\text { for me to control my } \\
\text { anxiety. }\end{array}$ & 1 & 2 & 3 & 4 & 5 \\
\hline $\begin{array}{l}\text { 17. When faced with a } \\
\text { difficult situation, I like } \\
\text { to collect all information } \\
\text { about it that I can. }\end{array}$ & 1 & 2 & 3 & 4 & 5 \\
\hline $\begin{array}{l}\text { 18. I have not told a lie } \\
\text { in my life. }\end{array}$ & 1 & 2 & 3 & 4 & 5 \\
\hline $\begin{array}{l}\text { 19. I'm optimistic about } \\
\text { most things I do. }\end{array}$ & 1 & 2 & 3 & 4 & 5 \\
\hline $\begin{array}{l}\text { 20. My friends tell me } \\
\text { intimate things about } \\
\text { themselves. }\end{array}$ & 1 & 2 & 3 & 4 & 5 \\
\hline $\begin{array}{l}\text { 21. In the past few years, } \\
\text { I've accomplished little. }\end{array}$ & 1 & 2 & 3 & 4 & 5 \\
\hline $\begin{array}{l}\text { 22. I tend to explode } \\
\text { with anger easily. }\end{array}$ & 1 & 2 & 3 & 4 & 5 \\
\hline $\begin{array}{l}\text { 23. I like to get an } \\
\text { overview of a problem } \\
\text { before trying to solve it. }\end{array}$ & 1 & 2 & 3 & 4 & 5 \\
\hline $\begin{array}{l}\text { 24. I have not broken a } \\
\text { law of any sort. }\end{array}$ & 1 & 2 & 3 & 4 & 5 \\
\hline $\begin{array}{l}\text { 25. I care what happens } \\
\text { to other people. }\end{array}$ & 1 & 2 & 3 & 4 & 5 \\
\hline $\begin{array}{l}\text { 26. It's hard for me to } \\
\text { enjoy life. }\end{array}$ & 1 & 2 & 3 & 4 & 5 \\
\hline $\begin{array}{l}\text { 27.It's hard for me to } \\
\text { make decisions on my } \\
\text { own. }\end{array}$ & 1 & 2 & 3 & 4 & 5 \\
\hline
\end{tabular}




\begin{tabular}{|c|c|c|c|c|c|}
\hline $\begin{array}{l}\text { 28.I have strong } \\
\text { impulses that are hard to } \\
\text { control. }\end{array}$ & 1 & 2 & 3 & 4 & 5 \\
\hline $\begin{array}{l}\text { 29. When facing a } \\
\text { problem, the first thing I } \\
\text { do is stop and think. }\end{array}$ & 1 & 2 & 3 & 4 & 5 \\
\hline $\begin{array}{l}\text { 30. I don't have bad } \\
\text { days. }\end{array}$ & 1 & 2 & 3 & 4 & 5 \\
\hline $\begin{array}{l}\text { 31. I am satisfied with } \\
\text { my life. }\end{array}$ & 1 & 2 & 3 & 4 & 5 \\
\hline $\begin{array}{l}\text { 32. My close } \\
\text { relationships mean a lot } \\
\text { to me and my friends. }\end{array}$ & 1 & 2 & 3 & 4 & 5 \\
\hline $\begin{array}{l}\text { 33. It's hard to express } \\
\text { my intimate feeling. }\end{array}$ & 1 & 2 & 3 & 4 & 5 \\
\hline 34.I'm impulsive. & 1 & 2 & 3 & 4 & 5 \\
\hline $\begin{array}{l}\text { 35. When trying to solve } \\
\text { a problem, I look at each } \\
\text { possibility and then } \\
\text { decide on the best way. }\end{array}$ & 1 & 2 & 3 & 4 & 5 \\
\hline $\begin{array}{l}\text { 36. I have not been } \\
\text { embarrassed for anything } \\
\text { that I've done. }\end{array}$ & 1 & 2 & 3 & 4 & 5 \\
\hline 37. I get depressed. & 1 & 2 & 3 & 4 & 5 \\
\hline $\begin{array}{l}\text { 38. I'm able to respect } \\
\text { others. }\end{array}$ & 1 & 2 & 3 & 4 & 5 \\
\hline $\begin{array}{l}\text { 39. I'm more of a } \\
\text { follower than a leader. }\end{array}$ & 1 & 2 & 3 & 4 & 5 \\
\hline $\begin{array}{l}\text { 40. I’ve got a bad } \\
\text { temper. }\end{array}$ & 1 & 2 & 3 & 4 & 5 \\
\hline $\begin{array}{l}\text { 41. In handling situations } \\
\text { that arise, I try to think of } \\
\text { as many approaches as I } \\
\text { can. }\end{array}$ & 1 & 2 & 3 & 4 & 5 \\
\hline $\begin{array}{l}\text { 42.I generally expect } \\
\text { things will turn out all } \\
\text { right, despite setbacks } \\
\text { from time to time. }\end{array}$ & 1 & 2 & 3 & 4 & 5 \\
\hline $\begin{array}{l}\text { 43. I'm sensitive to the } \\
\text { feelings of others. }\end{array}$ & 1 & 2 & 3 & 4 & 5 \\
\hline $\begin{array}{l}\text { 44. Others think that I } \\
\text { lack assertiveness. }\end{array}$ & 1 & 2 & 3 & 4 & 5 \\
\hline 45. I'm impatient. & 1 & 2 & 3 & 4 & 5 \\
\hline $\begin{array}{l}\text { 46. I believe in my } \\
\text { ability to handle most }\end{array}$ & 1 & 2 & 3 & 4 & 5 \\
\hline
\end{tabular}




\begin{tabular}{|c|c|c|c|c|c|}
\hline $\begin{array}{l}\text { 47. I have good } \\
\text { relationships with others. }\end{array}$ & 1 & 2 & 3 & 4 & 5 \\
\hline $\begin{array}{l}\text { 48. It's hard for me to } \\
\text { describe my feelings. }\end{array}$ & 1 & 2 & 3 & 4 & 5 \\
\hline $\begin{array}{l}\text { 49. Before beginning } \\
\text { something new, I usually } \\
\text { feel that I'll fail. }\end{array}$ & 1 & 2 & 3 & 4 & 5 \\
\hline $\begin{array}{l}\text { 50. It's difficult for me to } \\
\text { stand up for my rights. }\end{array}$ & 1 & 2 & 3 & 4 & 5 \\
\hline $\begin{array}{l}51 . \text { People think that I'm } \\
\text { sociable. }\end{array}$ & 1 & 2 & 3 & 4 & 5 \\
\hline
\end{tabular}

BarOn EQ-I:S Subscale Composition (underlined means reverse scored)

Intrapersonal: $\underline{3}, \underline{9}, \underline{15}, \underline{21}, \underline{27}, \underline{33}, \underline{39}, \underline{44}, \underline{48}, \underline{50}$

Interpersonal: 2, $\underline{8}, 14,20,25,32,38,43,47,51$

Stress Management: $\underline{4}, \underline{10}, \underline{16}, \underline{22,28}, \underline{34}, \underline{40}, \underline{45}$

Adaptability: 5,11,17,23,29,35,41

General Mood: 1,7,13,19,26,31, $\underline{37}, 42,46,49$

Positive Impression: 6,12,18,24,30,36 
Appendix B: Parent/Child Interaction Coding Manual

$\underline{\text { Definition }}$

CHILD BID

A child bid is any action, verbal or nonverbal, that suggests the desire for interaction with a parent.

\section{$\underline{\text { Bid Types }}$}

1. Bids can take the form of verbal direct requests that invite interaction

Examples

- Will you play with me

- You be the mother, I'll be the father

- So...what did you do today

- Put that block here

- Look at this

- Build a tower

- Look (with a point)

- See (with a point)

- Tell me

\section{Decision Rules}

- Direct request bids are not coded if the child simply needs assistance to then do something on his or her own (like asking mom to hand a Lincoln log that fell on floor but then obviously wants to build by himself and has no intention of engaging mom)

- A direct request bid CAN BE a request for conversation such as the mother trying to initiate a conversation with child

- Direct commands generally begin with the imperative verb, but may be preceded by "please”, the child's name, or "you"

- Direct commands are always "positive” commands (i.e., they tell the child what to do rather than what not to do)

2. Bids can take the form of verbal indirect requests that suggest the desire for interaction; verbal requests that are being hinted at but not directly stated

Examples

- I can't be the mother and father

- I need someone to play with me

- It's not fun to play alone

\section{$\underline{\text { Decision Rules }}$}


- Indirect requests can occur when a child is afraid to ask explicitly

3. Bids can take the form of a nonverbal join/intervene into a parent's activity Examples

- A parent is building a structure with the Lincoln logs and the child starts helping to build the same structure

- A parent is holding two puppets making them "talk" to each other and the child picks up a puppet and joins in the puppets' conversation

\section{Decision Rules}

- Code join/intervene if a child jumps into what his or her parent is doing

4. Bids can take the form of a nonverbal intentional touch that invites interaction

Examples

- Giving " 5 "- this invites the other party to share in a happy moment

- Crawling into the parent's lap-may be requesting comfort

- Leaning on the parent

Decision Rules

- Code intentional touch inviting, leading, or comforting touch that invites interaction

5. Bids can take the form of a nonverbal gesture that invites interaction

Examples

- Motioning to "come here" without saying anything

- Pointing to something and then picking it up

Decision Rules

- Code a gesture if the child is motioning to come here or pointing for the parent to look at something without speaking-if the child speaks in conjunction with the gesture, the bid would be coded as a verbal direct or indirect request

Codes

\begin{tabular}{|l|l|}
\hline 1 & Gesture \\
\hline 2 & Join/intervene \\
\hline 3 & Intentional Touch \\
\hline 4 & Indirect Request \\
\hline 5 & Direct Request \\
\hline
\end{tabular}

Variables

- Bidtype-categorical (see codes) 
$\underline{\text { Definition }}$

\section{PARENT RESPONSE TO CHILD BID}

Parent response to child bids for interaction is a part of parent sensitivity and responsiveness

\section{$\underline{\text { Response Types }}$}

1. A Parent can respond to a child's bid for interaction with an Accept-engage, active, response

Examples

- The child says he or she wants to play school with the puppets and then the parent picks up a puppet and asks if she should be the teacher or the student

\section{Decision Rules}

- Code accept-engage if the response in active, which both acknowledges the bid for interaction and then engages with the child, adds on, or elaborates something the child says or does

2. A Parent can respond to a child's bid for interaction with an Accept-acknowledge, passive, response

Examples

- The child says he or she wants to play school with the puppets and then the parent says "okay" but does not say or do anything further

\section{Decision Rules}

- Code accept-acknowledge if the response in passive, which acknowledges the bid for interaction or repeats what is said, acknowledging awareness of the bid but does not engage with the child, add on, or elaborate something the child says or does

3. A Parent can respond to a child's bid for interaction with an Ignore response

Examples

- The child says he or she wants to play school with the puppets but the parent acts as if she did not hear the bid and does not say or do anything

\section{Decision Rules}

- Code ignore if the parent obviously hears the child's bid but ignores the child by not saying or doing anything. 
4. A Parent can respond to a child's bid for interaction with a Reject response

Examples

- The child says he or she wants to play school with the puppets but the parent says "that's no fun"

- The child says he or she wants to play basketball with the balls and trash can but the parent says "no, I won't play that"

- Parent says “you’re disgusting”

\section{Decision Rules}

- Code reject if the parent responds in a way that acknowledges their awareness of the child's bid but denies the request.

- Children often appear hurt or upset after a reject response

Codes

\begin{tabular}{|l|l|}
\hline 0 & Reject \\
\hline 1 & Ignore \\
\hline 2 & Accept-Acknowledge \\
\hline 3 & Accept-Engage \\
\hline
\end{tabular}

$\underline{\text { Variables }}$

- Meanparresponse-mean of categorical response types (see codes) for all bids during the interaction

- Num_reject—count of total reject responses during the interaction

- Num_ignore-count of total ignore responses during the interaction

- Num_acknow_ — count of total accept-acknowledge responses during the interaction

- Num_Engage_ — count of total accept-engage responses during the interaction

- Lack_consistency_count of the response types used during the interaction period 
Appendix C: Informed Consent Form

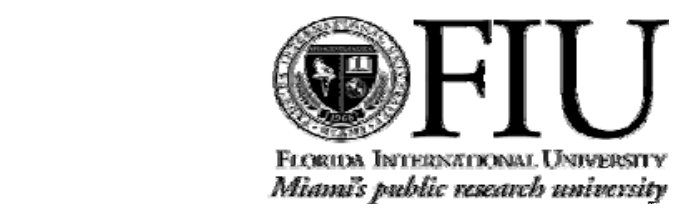

\section{CONSENT TO PARTICIPATE IN A RESEARCH STUDY Title: “The Child Development \& Family Enrichment Project”}

Form A

We would like you and your child to be in a research study. The investigator of this study is Dr. Marilyn Montgomery and she works at FIU. The study will include about 25 families with school-age children. We are conducting this study to learn more about parent-child relationships and children's healthy development. We also want to know how helpful the information is that we give to parents.

We will give your child a form to explain the study and find out if he/she wants to be in it. If you both decide to be a part of the study, you will come together to the Youth and Family Development Program (YFDP) at Florida International University (DM 268). The study will require about 4 hours of your time and about 2 hours of your child's time. Each time we meet or talk on the phone will take about an hour.

At the first visit, you and your child will be videotaped as you play some games and rate how fun the games are. You will complete a survey about your challenges as a parent. You will also complete a survey about how your child is doing at home, school, and with friends. Your child will complete a similar survey about how they are getting along with their friends, teachers, and family. At the second visit, you will discuss with Dr. Montgomery or one of her Research Assistants any concerns you have about your child's behavior or development. At the same time, your child will play with some toys, games, and art materials with one of the YFDP Research Assistants in the YFDP playroom. Your child will be videotaped so that we can look carefully at your child's development in several areas. You will return one more time by yourself. This time you will receive a feedback report about the strengths and overall development of your child, and we will offer suggestions for improvements that build on these strengths. About 6 weeks later we will call you to see how you and your child are doing.

There are no known risks related to the surveys or the videotaping. They have been used in other studies involving children. You may skip questions that you do not want to answer. If you feel discomfort at any time, you may ask to take a break. If your child becomes anxious or upset we will take a break. There is no cost or payment to you as a subject. You or your child may not gain anything from being in the study. However, your help will help us learn about the kind of information that parents find helpful. In addition, you may learn about new ways to help your child. At the end of the second session you and your child will get a small gift as a thank you for being in the study.

A number, not your names, will identify your information. All of your answers are private and will not be shared with anyone unless required by law. We will present the research results as a group at conferences and in a paper. You may ask questions about the study at any time. You and your child may withdraw at any time. If you choose not to continue in the study, no one will be upset with you.

If you would like more information about this research after you are done, you can contact me, Dr. Montgomery, at 305-348-6679. If you would like to talk with someone about your rights of being a subject in this study you may contact Dr. Patricia Price, the Chairperson of the FIU Institutional Review Board at 305348-2618 or 305-348-2494.

If you have had all of your questions answered to your liking and you would like to be in the study, sign below. Your signature also indicates that you will allow your child, study.

Print child's name , to be in the

$\overline{\text { Signature of Participant }} \quad$ Printed Name $\quad$ Date

I have explained the research procedure and participant rights and answered questions asked by the participant. I have offered him/her a copy of this informed consent form. 
VITA

\section{MELODY WHIDDON}

2003

2003-2008

2005

2008-Present

2008-Present
B.S, Psychology

Kennesaw State University

Kennesaw, GA

Lab Manager

Youth and Family Development Program

Florida International University

Miami, Florida

M.S., Counseling Psychology

Florida International University

Miami, Florida

Licensed Mental Health Counselor Intern

State of Florida

Instructor of Psychology

Florida International University

Miami, FL

\section{PUBLICATIONS AND PRESENTATIONS}

Whiddon, M., Montgomery, M., \& Collado-Rodriguez, A. (In Prep). Emotional Intelligence: A Manifestation of Attachment and the Internal Working Model, Submitted to Attachment and Human Development.

Whiddon, M. \& Montgomery, M. (In Prep). Attachment Theory Explains the Relationships between Parent Emotional Functioning, Parent-Child Interaction, and Child Adjustment, Submitted to Developmental Review.

Whiddon, M. \& Montgomery, M. (In Prep). Physical Touch during Parent-Child Play in Relation to Child Psychological Adjustment. Submitted to Behavior Development Bulletin.

Whiddon, M. \& Montgomery, M., (2009), Physical Touch during Parent-Child Interaction and Child Psychological Adjustment (Poster), Society for Research on Child Development, April 2009

Whiddon, M. \& Montgomery, M. (2009), Parent-Child Interaction as a Mediator of Child Adjustment (Poster), Society for Research on Child Development, April 2009 
Cici-Gokaltun, A., Montgomery, M., Whiddon, M., \& Levitt, M. (2009). The Impact of Parent Differentiation of Self on Positive Family Functioning (Poster), Society for Research on Child Development, April 2009 